\title{
2011s-16
}

\section{Past Market Variance and Asset Prices}

\author{
Federico M. Bandi, Benoit Perron
}

\begin{tabular}{c}
\hline Série Scientifique \\
Scientific Series
\end{tabular}

\author{
Montréal \\ Cette version mars 2010 \\ This version March 2010 \\ (CIRANO publication : février 2011/February 2011)
}

(C) 2011 Federico M. Bandi, Benoit Perron. Tous droits réservés. All rights reserved. Reproduction partielle permise avec citation du document source, incluant la notice (C).

Short sections may be quoted without explicit permission, if full credit, including (C) notice, is given to the source.
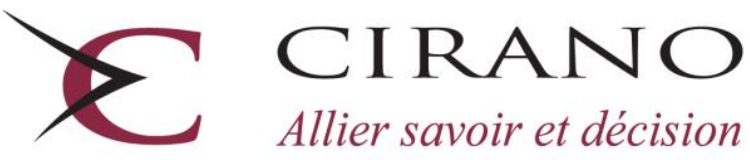

Allier savoir et décision

Centre interuniversitaire de recherche en analyse des organisations 


\section{CIRANO}

Le CIRANO est un organisme sans but lucratif constitué en vertu de la Loi des compagnies du Québec. Le financement de son infrastructure et de ses activités de recherche provient des cotisations de ses organisations-membres, d'une subvention d'infrastructure du Ministère du Développement économique et régional et de la Recherche, de même que des subventions et mandats obtenus par ses équipes de recherche.

CIRANO is a private non-profit organization incorporated under the Québec Companies Act. Its infrastructure and research activities are funded through fees paid by member organizations, an infrastructure grant from the Ministère du Développement économique et régional et de la Recherche, and grants and research mandates obtained by its research teams.

\section{Les partenaires du CIRANO}

Partenaire majeur

Ministère du Développement économique, de l'Innovation et de l'Exportation

\section{Partenaires corporatifs}

Banque de développement du Canada

Banque du Canada

Banque Laurentienne du Canada

Banque Nationale du Canada

Banque Royale du Canada

Banque Scotia

Bell Canada

BMO Groupe financier

Caisse de dépôt et placement du Québec

Fédération des caisses Desjardins du Québec

Financière Sun Life, Québec

Gaz Métro

Hydro-Québec

Industrie Canada

Investissements PSP

Ministère des Finances du Québec

Power Corporation du Canada

Raymond Chabot Grant Thornton

Rio Tinto

State Street Global Advisors

Transat A.T.

Ville de Montréal

\section{Partenaires universitaires}

École Polytechnique de Montréal

HEC Montréal

McGill University

Université Concordia

Université de Montréal

Université de Sherbrooke

Université du Québec

Université du Québec à Montréal

Université Laval

Le CIRANO collabore avec de nombreux centres et chaires de recherche universitaires dont on peut consulter la liste sur son site web.

Les cahiers de la série scientifique (CS) visent à rendre accessibles des résultats de recherche effectuée au CIRANO afin de susciter échanges et commentaires. Ces cahiers sont écrits dans le style des publications scientifiques. Les idées et les opinions émises sont sous l'unique responsabilité des auteurs et ne représentent pas nécessairement les positions du CIRANO ou de ses partenaires.

This paper presents research carried out at CIRANO and aims at encouraging discussion and comment. The observations and viewpoints expressed are the sole responsibility of the authors. They do not necessarily represent positions of CIRANO or its partners. 


\title{
Past Market Variance and Asset Prices *
}

\author{
Federico M. Bandi ${ }^{\dagger}$, Benoit Perron ${ }^{+}$
}

\begin{abstract}
Recent work in asset pricing has focused on market-wide variance as a systematic factor and on firm-specific variance as idiosyncratic risk. We study an alternative channel through which the variability of financial market returns may help our understanding of cross-sectional price formation in financial markets. Invoking the countercyclical nature of market variance, we allow the (stochastic) discounting of future cash-flows to depend on the level of past market variance $(p m v)$. Employing $p m v$ as a conditioning variable in a classical consumption-CAPM framework, we derive economically meaningful conditional factor loadings and conditional risk premia. We show that scaling by $p m v$ may also yield more effective pricing results than scaling by successful, alternative variables (such as the consumption-to-wealth ratio) precisely at frequencies at which their predictive ability for excess market returns should be (in theory) and is (empirically) maximal, i.e., business-cycle frequencies.
\end{abstract}

Keywords: Asset prices, financial markets.

\footnotetext{
* We thank Eric Jacquier, Pietro Veronesi, and participants in the Financial Econometrics Conference at Imperial College, London (May, 2008), and the Inaugural Meetings of the Society for Financial Econometrics (SoFiE) for helpful comments. Financial support from the William S. Fishman Faculty Research Fund at the Graduate School of Business of the University of Chicago (Bandi) and FQRSC, SSHRC, and MITACS (Perron) is gratefully acknowledged. Both authors also thank the Initiative on Global Markets at the Booth School of Business of the University of Chicago for providing further funding. We are grateful to Martin Lettau, Sydney Ludvigson, Gene Fama, and Ken French for making their data available.

${ }^{\dagger}$ Booth School of Business, University of Chicago. Address: 5807 South Woodlawn Avenue, Chicago, IL, 60637, USA. Tel.: (773) 834-4352. E-mail: federico.bandi@ chicagogsb.edu.

${ }^{\ddagger}$ Dépt. de sciences économiques, Université de Montréal, CIREQ and CIRANO, C.P. 6128, Succ. centre-ville, Montréal, Québec, H3C 3J7, Canada. Tel. (514) 343-2126. E-mail: benoit.perron@umontreal.ca.
} 


\section{Introduction}

We conjecture that the level of past financial market variance might have an important effect on the way market participants risk-adjust, or discount, future cash flows for the purpose of cross-sectional asset pricing. Specifically, the (stochastic) discounting of future pay-offs may depend on the state of the economy, as summarized by the level of financial market variance. Differently put, it is often assumed that the relevant notion of cross-sectional risk is not the unconditional beta of an asset but its conditional (on the state of the economy) counterpart. We conjecture that past market variance may serve as an economically-meaningful sufficient statistic when computing conditional (on the state of the economy) cross-sectional betas.

The macroeconomic determinants of financial market variance are rather uncontroversial. Higher volatility of output growth, inflation, and interest rates translate into higher market variance. High inflation and low output growth are also associated with high market variance (see, e.g., Engle and Gonzalo, 2008). Hence, higher variance tends to be associated with weak economic conditions. It may also be induced by related (to the prevailing economic conditions) changes in risk-aversion as well as by changes in investor's uncertainty about fundamentals (when this uncertainty is priced in equilibrium). In other words, market-wide financial variance may correlate in important ways with the state of the economy, both in terms of macro fundamentals and in terms of market participants's sentiment about fundamentals. This said, while consumption risk may be the relevant priced risk as postulated by classical cross-sectional pricing paradigms, we conjecture that the impact of consumption risk on the cross-sectional prices of financial assets (i.e., their consumption betas) might change depending on the prevailing variance level. This is the sense in which market variance may serve, in terms of cross-sectional pricing, as a sufficient statistic for the state of macro economic fundamentals as well as for the state of agents' uncertainty about fundamentals and changes in risk preferences.

Using ubiquitous test assets, such as portfolios sorted on size and book-to-market, we confirm this intuition. Differently from much existing work in asset pricing, we evaluate equilibrium pricing at alternative frequencies ranging from 1 quarter to 40 quarters (10 years) with a focus on (roughly) business-cycle frequencies (2 to 5 years). Specifically, we show that the value and size premium (i.e., the higher average returns delivered by high book-to-market/small capitalization stocks) may be the results of porfolios of small companies and value companies having relatively higher risk (higher betas with respect to consumption growth) in less favorable times (i.e., in times of high market variance).

Our approach and results relate to a broad recent literature on conditional or scaled pricing. In the context of traditional pricing paradigms, such as the consumption-CAPM, meaningful choices of the conditioning variable(s) have been shown to deliver smaller pricing errors than 
those implied by the corresponding unconditional models. These pricing errors often fare satisfactorily when compared to the ones yielded by well-known benchmarks, such as the FamaFrench three-factor model. Implementing conditional models, however, is not an obvious task. While economic theory places restrictions on the set of viable conditioning variables, timevariation in the stochastic discount factor naturally depends on the agents' utility function and its inputs. Hence, even though variables tracking predictable changes in the conditional moments of market returns are natural candidates, the set of possible conditioning variables is broad and, for obvious reasons, hard to completely pin down. Importantly, even when clearly implied by a model, these variables may be unobservable, the surplus consumption ratio of Campbell and Cochrane (1999) being a notorious example.

Relying on the countercyclical nature of variance, we show that past market variance $(p m v)$ may serve as an easily-computable proxy for macro variables driving state dependence in the stochastic discount factor. Conditioning on $p m v$ drastically improves on the performance of the classical C-CAPM leading to pricing errors that are similar to those induced by the Fama-French three-factor model and are often smaller than those implied by the successful consumption-to-wealth ratio (cay) advocated by Lettau and Ludvingson (2003). Between 2 and 5 years, when conditioning on pmv, the scaled C-CAPM explains 55.6\%, 70.9\%, 69.2\%, and $54.5 \%$ of the variation in average retiurns. The corresponding values for the unconditional C-CAPM and the C-CAPM conditional on cay are $24.7 \%, 16.2 \%, 8.6 \%,-0.9 \%$ and $46.3 \%$, $35.9 \%, 33.1 \%, 37.2 \%$, respectively. The limitations of using purely statistical metrics (such as coefficients of determinations) when evaluating unconditional and conditional asset pricing models are of course well-known (for recent discussions, Lewellen and Nagel, 2006, and Lewellen et al., 2007). The above figures should therefore be interpreted as being merely suggestive. The remainder of the paper places emphasis on the economic implications of our problem.

As said, proper conditioning of the stochastic discount factor should rely on variables that have explanatory power for the conditional moments of market returns. Bandi and Perron (2008) document that the predictive ability of $p m v$ for excess market returns increases with the aggregation horizon. In the long run, $p m v$ is a much stronger predictor of excess market returns than both the classical dividend-yield $(d y)$ and cay. Admittedly, in conditional pricing models, the dependence between conditional moments of market returns and conditioning variables is, in general, nonlinear. However, the predictive ability of $p m v$ in linear models for conditional expected market returns (and conditional variances) makes $p m v$, as is the case for $d y$ and cay in the recent literature, a viable candidate for a theoretically-meaningful conditioning variable. We evaluate the cross-sectional pricing implications of this time-series predictability and show that $p m v$ may lead to effective time-variation in cross-sectional consumption risk. 
A vast amount of recent work has been devoted to the relevance of variance in asset pricing tests. The existing work has focused on innovations in market variance employed as a systematic factor found to be priced cross-sectionally (see, e.g., Adrian and Rosenberg, 2008, Ang et al., 2006, Bandi et al., 2008, and Moise, 2006) as well as on the residual cross-sectional pricing of idiosyncratic variance beyond that provided by a variety of widely-employed systematic factors (Ang et al., 2006, and Spiegel and Wang, 2005, among others). This paper suggests an alternative channel (i.e., time-variation in the stochastic discount factor) through which market variance may help our understanding of price formation in financial markets.

The remainder of the paper is structured as follows. Section 2 provides, in the context of modern approaches to asset pricing, economic motivation for deriving easy-to-compute proxies for variables driving state dependence in the stochastic discount factor. As previously pointed out, our results suggest that $p m v$ may be one such proxy. Section 3 introduces the data and the $p m v$ estimator in a fairly general continuous-time setting. In Section 4 we present motivating findings about the cross-sectional relation between the returns on the size- and value-sorted portfolios and $p m v$. Section 5 discusses conditional (on $p m v$ ) cross-sectional pricing at business-cycle frequencies and in the long run. In Section 6 we compare our pricing results to alternative, successful models, namely the classical Fama-French three-factor model and scaled specifications relying on cay. Section 7 discusses issues of robustness in the context of recent criticisms of conditional approaches to cross-sectional pricing. Section 8 is about economic interpretation through analysis of the model's implied conditional betas and implied conditional risk premia. Section 9 concludes.

\section{Modern utility functions}

The price of a claim to consumption can be expressed as $P_{t}^{M}=\frac{1}{\pi_{t}} E_{t}\left[\int_{t}^{\infty} \pi_{\tau} C_{\tau} d \tau\right]$, where $C_{t}$ denotes consumption and $\pi_{t}$ is the state-price density which discounts future consumption streams. Consider the state price density $\pi_{t}=e^{-\rho t} C_{t}^{-\gamma} H_{t}$, where $H_{t}$ is a slow-moving utility adjustment. This is a fairly general specification in modern asset pricing theory including, among other recent models, the external habit of Campbell and Cochrane (1999) and Santos and Veronesi (2005) as well as broadly defined shocks to preferences or changes in sentiment as in, e.g., Lettau and Wachter (2007). In the former case, $H_{t}=S_{t}^{-\gamma}$ with $S_{t}=\left(C_{t}-X_{t}\right) / C_{t}$, i.e., the surplus consumption ratio.

Importantly, the assumed state-price density implies that the conditional moments of market returns are nonlinear functions of the utility adjustment $H_{t}$. Differently put, focusing on the first two conditional moments, $E_{t}\left[R_{t, t+1}^{M}\right]=f_{1}\left(H_{t}\right)$ and $V_{t}\left[R_{t, t+1}^{M}\right]=f_{2}\left(H_{t}\right)$, for generic functions $f_{1}($.$) and f_{2}($.$) .$ 
Importantly, the utility-adjustment $H_{t}$ is unobservable, in general. Hence, proper conditioning on $H_{t}$ for the purpose of cross-sectional pricing cannot be conducted. We ask the question: does $p m v$ correlate in important ways with the unobservable $H_{t}$ ? Alternatively, is $p m v$ driving time-series variation in the conditional first and second moment of market returns? Admittedly, these are hard questions to answer because of the unobservability of $H_{t}$ and that of the driving functions $f_{1}($.$) and f_{2}($.$) . They are also hard questions to answer in$ light of the lack of theoretical implications about the horizon at which asset pricing models should perform satisfactorily. Put it differently, at which frequency should we be evaluating the forecasting performance (for market returns and future market variance) of $p m v$ ? Similarly, at which frequency should cross-sectional pricing exercises be conducted?

Addressing these fundamental issues satisfactorly is naturally beyond the scope of this paper. However, by $(i)$ reporting the outcomes of linear regressions of future market returns and future market variances on to $p m v$ and ( $i i)$ by doing so at a variety of alternative horizons, the next section provides preliminary evidence about the viability of $p m v$ as a proper conditioning variable in cross-sectional pricing. The pricing performance of $p m v$ is the subject of the following sections.

\section{Data and time-series regressions}

While our emphasis is on business-cycle frequencies, we report conditional pricing results at various horizons ranging from 1 quarter to 10 years. To this extent, we use data between the second quarter of 1952 and the last quarter of 2006 and aggregate it over the appropriate horizon $h$ (with $h=1, \ldots, 40$ ), as we discuss below.

There are two reasons for employing the quarterly frequency as our highest data frequency. First, quarterly consumption data to be used in implementations of the C-CAPM (and its conditional variations) is available over a longer time span. Monthly consumption data only starts in $1959 .^{1}$ Second, we deem it informative to compare the cross-sectional pricing ability of $p m v$ to that of cay. The latter is obtained as the residual from a cointegrating regression of logarithmic consumption on logarithmic financial wealth and logarithmic labor income (all variables measured per-capita and in real terms) and is available at the quarterly frequency. ${ }^{2}$

As is customary, we use the CRSP value-weighted index with dividends as our market proxy. This series is available daily. This higher (daily) frequency is exploited for constructing the $p m v$ estimator, as outlined below.

\footnotetext{
${ }^{1}$ The consumption data is real per-capita consumption on nondurables and services. We use the modified version of this series (which excludes clothing and shoes) available on Sidney Ludvigson's web site.

${ }^{2}$ We also obtain it from Sydney Ludvigson's web site.
} 
Our test assets are the 25 Fama-French size- and value-sorted portfolios. ${ }^{3}$ The Fama-French portfolio returns are available at the monthly frequency. We convert them to quarterly data (and data at lower frequencies) by aggregating appropriately.

\subsection{Past market variance $(p m v)$}

We employ realized variance to identify sample path variation in observed market returns and compute $p m v$. Consider a generic quarter $t$ with $n_{t}$ trading days. Denote by $r_{t+\frac{j}{n_{t}}}$ the $j$-th daily continuously-compounded return in quarter $t$. Realized variance in quarter $t$ is given by

$$
\widehat{\sigma}_{t, t+1}^{2}=\sum_{j=1}^{n_{t}} r_{t+\frac{j}{n_{t}}}^{2}
$$

i.e., the sum of the (daily) squared continuously-compounded returns over the period. It is wellknown that, under assumptions, $\widehat{\sigma}_{t, t+1}^{2}$ is a consistent estimate of (increments in) the quadratic variation of the logarithmic price process in asymptotic designs allowing for $n_{t} \uparrow \infty$ for all $t$ (i.e., as the number of observations in each quarter increases asymptotically without bound). For instance, assume the logarithmic price process is expressed as $\log p_{t}=\Phi_{t}^{f}+\Phi_{t}^{l}+\Phi_{t}^{j}$, where $\Phi_{t}^{f}$ is a continuous finite variation component, $\Phi_{t}^{l}=\int_{0}^{t} \sigma_{s} d W_{s}$ is a local martingale driven by Brownian shocks $d W_{t}, \Phi_{t}^{j}=\int_{0}^{t}\left(J_{s} d Z_{s}-\mu_{j} \lambda_{s} d s\right)$ is a compensated, jump process with $Z_{t}$ denoting a counting process with finite intensity $\lambda_{t}$, and $J_{t}$ is a random jump size with mean $\mu_{j}$ and variance $\sigma_{j}^{2}$. Furthermore, assume the stochastic volatility process $\sigma_{s}$ is càdlàg. This specification readily accommodates small and large shocks in the price's sample path as well as fairly unrestricted spot volatility dynamics. The quadratic variation of the continuous-time Markov process $\log p_{t}$ between $t$ and $t+1$ is

$$
[\log p]_{t, t+1}=[\log p]_{t+1}-[\log p]_{t}=\int_{t}^{t+1} \sigma_{s}^{2} d s+\sum_{t \leq s \leq t+1}\left(\log \left(p_{s}\right)-\log \left(p_{s-}\right)\right)^{2},
$$

where $\log \left(p_{s-}\right)=\lim _{\eta \downarrow 0} p_{s-\eta}$, and is made up of two components, one associated with variation in the local martingale and one deriving from the presence of infrequent jumps in the sample path. Andersen et al. (2003) and Barndorff-Nielsen and Shephard (2002) have recently provided empirical and theoretical justifications for the use of realized variance in the presence of high-frequency asset price data under similar assumptions. As is traditional in low frequency applications in finance, we do not take the asymptotics literally. Nevertheless, our use of daily

\footnotetext{
${ }^{3}$ As in Fama and French $(1992,1993)$, we work with portfolios constructed by value-weighing stock returns (on the New York Stock Exchange, the American Stock Exchange, and the Nasdaq) at the intersection of five size quintiles and five book-to-market quintiles. The portfolio's raw returns were downloaded from Kenneth French's web site. We refer the reader to it for details on portfolio construction.
} 
data in the computation of $p m v$ is bound to capture important variation in the market return's sample path. Thus, $p m v_{t-h, t}$ is simply defined as $\widehat{\sigma}_{t-h, t}^{2}$, where

$$
\widehat{\sigma}_{t, t+h}^{2}=\sum_{i=1}^{h} \widehat{\sigma}_{t+i-1, t+i}^{2} .
$$

for an aggregation level equal to $h$ quarters.

\subsection{Some preliminary evidence}

Consistently with our discussion in Section 2, proper conditioning variables should have predictive ability for the moments of market returns. These moments may of course be highly nonlinear functions of the predictor(s), in general.

Define market returns between $t$ and $t+h$ as $R_{t, t+h}=\Pi_{j=1}^{h}\left(1+R_{t+\frac{j}{h}}\right)-1$, where $R_{t+\frac{j}{h}}$ is the $j$-th quarterly return on the market over horizon $h$. We regress $R_{t, t+h}$ and $\widehat{\sigma}_{t, t+h}^{2}$ (or, equivalently, $p m v_{t, t+h}$ ) on $p m v_{t-h, t}$. We do so at various horizons and report results in Table I. The regression of future market returns on $p m v$ largely replicates findings in Bandi and Perron (2008) where risk premia (market returns in excess of the risk-free rate) are regressed on $p m v$ : the predictive ability of $p m v$ increases with the horizon. Not surprisingly, future market variance is best predicted by $p m v$ at short horizons. This is an implication of the autoregressive nature of variance.

In the context of a traditional (in the existing literature) linear specification, this evidence, and the related evidence in Bandi and Perron (2008), are meant to be merely suggestive of the informational content of $p m v$ for the market return moments at various horizons. In what follows, we explore the cross-sectional pricing implications of this time-series predictability.

\section{Fama-French portfolio returns and $p m v$}

In order to further motivate our approach, we now report the outcomes of regressions of the 25 Fama-French portfolio returns on pmv. In light of the countercyclical nature of financial market variance, our interest is largely on business-cycle frequencies. To this extent, we focus here on aggregation levels between 1 and 5 years. As earlier in the market case, we define portfolio returns between $t$ and $t+h$ as $R_{t, t+h}^{p}=\Pi_{j=1}^{h}\left(1+R_{t+\frac{j}{h}}^{p}\right)-1$, where $R_{t+\frac{j}{h}}^{p}$ is the $j$-th return on portfolio $p$ over horizon $h$. We run the following regressions:

$$
R_{t, t+h}^{p}=\kappa_{h}^{p}+\beta_{h}^{p} p m v_{t-h, t}+\varepsilon_{t, t+h}^{p} \quad h=4,8,12,16,20 \quad p=1,2, \ldots, 25 .
$$

Table II contains the results. The betas of the 25 Fama-French portfolio returns with respect to $p m v$ decrease in the size dimension (when going from small firms to large firms) and increase 
in the value dimension (when going from low book-to-market stocks to high book-to-market stocks). In other words, at these frequencies, large firms generally yield returns that are less correlated with $p m v$ than small firms. Similarly, value stocks yield returns that are more correlated with pmv than growth stocks. These patterns reflect similar patterns in average returns. As is well-known, average returns increase with value and decrease with size. As expected, they do so at all frequencies we consider. While these obvious structures in the betas are sometimes not fully monotonic, they are somewhat striking. When paired with the cross-sectional dispersion of average returns, they appear indicative of the cross-sectional pricing potential of pmv. We now turn to a more formal discussion of this issue.

For a specific horizon $h$, write the fundamental pricing equation as

$$
1=\mathbf{E}_{t}\left[M_{t+h}\left(1+R_{t, t+h}^{p}\right)\right]
$$

where $\mathbf{E}_{t}$ denotes expectation conditional on time $t$ information, $M_{t+h}$ is the stochastic discount factor, and $R_{t, t+h}^{p}$ is, as earlier, the net return on the generic asset (portfolio, in our case) $p$. Assume $M_{t+h}=c_{1 t}+c_{2 t} f_{t, t+h}$, where $f_{t, t+h}$ is a factor. Classical models are the CAPM for which the factor $f_{t, t+h}$ is the market return over $h$ and the C-CAPM for which $f_{t, t+h}$ is consumption growth over the same horizon. Even though, for reasons of economic generality and consistency with theory as laid out in Section 2, our interest in this paper is in the consumption specification, in what follows we will report results pertaining to the CAPM case as well. In general, $c_{1 t}$ and $c_{2 t}$ are time-varying coefficients whose dependence on time $t$ macro variables depends on the true, unknown utility function. ${ }^{4}$ Write now $c_{1 t}=a_{1}+a_{2} x_{t}$ and $c_{2 t}=b_{1}+b_{2} x_{t}$. In other words, assume that time-variation in the level and slope of the stochastic discount factor is driven by a variable $x$ measurable with respect to time $t$ information. This specification, which could be readily extended to multiple states $x$, leads to

$$
1=\mathbf{E}\left[\left(a_{1}+a_{2} x_{t}+b_{1} f_{t, t+h}+b_{2}\left(x_{t} f_{t, t+h}\right)\right)\left(1+R_{t, t+h}^{p}\right)\right]
$$

with no need for a subscript $t$ on the expectation operator. In other words, it leads to an unconditional multifactor beta specification

$$
\mathbf{E}\left[R_{t, t+h}^{p}\right]=\mathbf{E}\left[\widetilde{R}_{t, h}\right]+\sum_{i=1}^{3} \beta_{h, i}^{p} \lambda_{h, i},
$$

where $\mathbf{E}\left[\widetilde{R}_{t, h}\right]$ is the expected return on the zero-beta portfolio uncorrelated with the stochastic discount factor (as in Black, 1972), the $\beta^{p}$ s are multivariate betas of the returns on asset $p$ on

\footnotetext{
${ }^{4}$ In Campbell and Cochrane (1999), for example, $c_{1 t}$ and $c_{2 t}$ are functions of the "surplus consumption ratio."
} 
$x_{t}, f_{t, t+h}$, and the interaction variable $x_{t} f_{t, t+h}$, and the $\lambda \mathrm{s}$ are the corresponding cross-sectional slopes. ${ }^{5}$

Assume now $x_{t}=p m v_{t-h, t}$. When combined with the observed pattern in average portfolio returns $\widehat{\mathbf{E}}\left[R_{t, t+h}^{p}\right]$, the reported structure in the estimated pmv betas (obtained from Eq. (3) above) is suggestive of the potential economic and statistical significance of the corresponding $\widehat{\lambda}$ estimate. Neglecting, but only for the time being, the additional loadings associated with the factor $f_{t, t+h}$ and the interaction $x_{t} f_{t, t+h}$, this significance is, in turn, indicative of the pricing potential of $p m v$ as a scaling variable.

In what follows, we evaluate the cross-sectional relation between average returns and genuinely multivariate betas and its economic implications. Differently put, we evaluate whether the level of historical market variance tracks meaningful predictable time-variation in the stochastic discount factor.

\section{Conditional (on $p m v$ ) pricing}

\subsection{Business-cycle frequencies}

We employ a standard two-pass methodology for testing asset pricing models. For each asset $p$ and horizon $h$, we first run a time-series regression of returns $\left(R_{t, t+h}^{p}\right)$ on $\overline{\mathbf{f}}_{t, t+h}=\left(x_{t}, f_{t, t+h}\right.$, $\left.x_{t} f_{t, t+h}\right)^{\top}$, namely

$$
R_{t, t+h}^{p}=\kappa_{h}^{p}+\left(\boldsymbol{\beta}_{h}^{p}\right)^{\top} \overline{\mathbf{f}}_{t, t+h}+\varepsilon_{t, t+h}^{p},
$$

to estimate the loadings in the vector $\boldsymbol{\beta}_{h}^{p}$. In the second step, for each horizon $h$, we run cross-sectional regressions of the average returns on the portfolios on the estimated loadings to evaluate the resulting pricing errors:

$$
\left(\frac{1}{T-h} \sum_{t=1}^{T-h} R_{t, t+h}^{p}\right)=\alpha_{h}+\boldsymbol{\lambda}_{h}^{\top} \hat{\boldsymbol{\beta}}_{h}^{p}+\varepsilon_{h} .
$$

For the time being, we focus on two unconditional models, the CAPM and the C-CAPM, and their scaled versions (by $p m v$ ). We report adjusted- $R^{2} \mathrm{~s}$ (in Table III) and estimated lambdas (in Table IV) from the second-step, cross-sectional regressions. The adjusted- $R^{2}$ values associated with the static CAPM and the static C-CAPM are, respectively, 17.5\%, $14.7 \%,-0.7 \%,-4.3 \%$ and $24.7 \%, 16.2 \%, 8.6 \%,-0.9 \%$, at 2 to 5 years. Hence, market returns and consumption growth perform similarly at these frequencies. Scaling by $p m v$ improves the overall fit significantly. The coefficients of determination of the scaled models are $48.2 \%$,

\footnotetext{
${ }^{5}$ Since $x_{t}$ is not a risk factor, in conditional models the lambdas do not have a direct economic interpretation in terms of market prices of risk (see, e.g., the discussion in Cochrane, 1996, 2004, and Lettau and Ludvingson, 2001b). Similarly, of course, the betas do not have a direct interpretation in terms of quantities of risk. We discuss these issues in Section 8.
} 
$61.3 \%, 43.6 \%, 33.2 \%$ and $55.6 \%, 70.9 \%, 69.2 \%, 54.5 \%$, thereby yielding a greater improvement in the C-CAPM case. Fig. 1 provides a graphical representation. The limitations of statistical metrics, such as coefficients of determination, to evaluate pricing models are notorious. Section 8 focuses on economic significance.

As previously suggested, the betas associated with pmv play an important role (Table IV). This is especially true in the CAPM case where the lambdas associated with these betas have minimum $t$-statistics above 2.4 at business-cycle frequencies. In the C-CAPM case both the beta on $p m v$ and the beta on the interaction matter at these frequencies. In particular, the estimated lambdas on the interaction have all $t$-statistics above 5.5. The lambdas on the market are negative but statistically insignificant. This is a typical result in the literature (see, e.g., the discussion in Lettau and Ludvigson, 2001b). The lambdas on consumption growth are instead positive and more statistically significant. In spite of the lack of interpretability of the lambdas in terms of market prices of risk in conditional models, this result is generally more consistent with standard economic logic. Ignoring other terms, one would expect stocks delivering higher average returns to be riskier, as implied by their higher return correlations with consumption growth. This risk should be positively priced in equilibrium.

For a clearer graphical assessment, Figs. 2 through 5 report the pricing errors associated with the static models (Fig. 2 and 4 ) and with the conditional models (Fig. 3 and 5). In particular, the values on the vertical axis are realized average returns on the portfolios, whereas the values on the horizontal axis are the corresponding fitted mean returns implied by each model (i.e., using estimated lambdas and betas). Naturally, if a model priced the portfolios exactly, the dots would sit on the 45 degree line. As always, for each value on the scatterplot, the first digit refers to the size quintile (with 1 indicating the smallest firms and 5 indicating the largest firms) and the second digit refers to the book-to-market quintile (with 1 indicating growth stocks and 5 indicating value stocks). The reduction in pricing errors yielded by $p m v$ scaling is apparent.

\subsection{The long run}

The adjusted- $R^{2}$ values of the static CAPM and C-CAPM at 9 and 10 years are $47.5 \%, 46.6 \%$ and $28.4 \%, 36.0 \%$, respectively. Therefore, the unconditional models perform somewhat better at low frequencies. In particular, market returns explain a larger portion of the cross-sectional variation of the Fama-French portfolios than consumption growth in the long run.

Scaling by $p m v$ increases the $R^{2}$-values to $65 \%$ and $70 \%$ in the CAPM case and to $69.5 \%$ and $74.8 \%$ in the C-CAPM case. The lambdas associated with the interaction are always positive and highly statistically significant (Table IV). The lambdas associated with the pmv's 
loadings are also positive. They are significant in the CAPM case and fairly insignificant in the C-CAPM case. While, in agreement with the static model, market returns play a more important role than consumption growth if considered individually, the joint consideration of the loadings with respect to the conditioning variable and the interaction yields smaller pricing errors in the C-CAPM case than in the CAPM case.

When taking the theoretical implications of Section 2 seriously, since $p m v$ strongly predicts long-run market returns as reported earlier (and extensively illustrated in Bandi and Perron, 2008), the improved fit delivered by pmv over the static C-CAPM should not be viewed as surprising. More generally, our findings suggest that $p m v$ may contain meaningful information about time-variation in the stochastic discount factor both at business-cycle frequencies and at lower frequencies.

\section{Alternative pricing models}

It is now informative to evaluate the pricing performance of scaled models using pmv as compared to existing successful alternatives, such as the classical Fama-French three-factor model and scaled specifications using cay. We begin with the latter.

Lettau and Ludvigson (2001a) have shown that cay, coherently with its theoretical justification, ${ }^{6}$ is a strong predictor of excess market returns at business-cycle frequencies. Table V supports this notion using our data. Consistent with its considerable predictive ability in the time series, Lettau and Ludvigson (2001b) have also shown that cay is a useful conditioning variable in scaled asset pricing models. We confirm this result. At business-cycle frequencies the adjusted- $R^{2}$ values yielded by cay in the CAPM case are $39.3 \%, 50.5 \%, 65.2 \%$, and $77.3 \%$. They are $46.3 \%, 35.9 \%, 33.1 \%$, and $37.2 \%$ in the C-CAPM case. These values should of course be compared to the adjusted $R^{2}$-values of the static models in Table III and Fig. 1. When doing so, models scaled by cay are found to clearly dominate their unconditional counterparts.

Interestingly, for our data, the pricing ability of $p m v$ compares favorably to that of cay both at business-cycle frequencies and in the long run. Importantly, this is particularly true in the CCAPM case. This finding may be appreciated by comparing adjusted- $R^{2}$ s. More interestingly for our purposes, it may be appreciated by examining the nature of the conditional factor loadings implied by alternative scaling factors. Needless to say, this is a more compelling metric, for our purposes. Session 8 discusses conditional (on cay and pmv) factor loadings for the C-CAPM. We show that, for our data, pmv leads to conditional consumption betas that are, in "bad states of the world," relatively more monotonically increasing with value and

\footnotetext{
${ }^{6} \mathrm{~A}$ high value of the consumption-to-wealth ratio implies either expectations of high returns on wealth or expectations of low consumption growth.
} 
relatively more monotonically decreasing with size. Additionally, $p m v$ leads to relatively larger spreads in the conditional consumption loadings than cay. Because the relevant notion of risk in conditional consumption models is covariation with consumption growth given the state of the economy, $p m v$ appears to perform satisfactorily at explaining differential average returns on portfolios by delivering risk quantities (i.e., conditional betas) which align fairly effectively with these average returns.

We conclude with the Fama-French three-factor model. As is well-known, the model uses the market returns, the returns on a "small minus big" (SMB) portfolio, and the returns on "high minus low" (HML) portfolio as the relevant factors. ${ }^{7}$ Hence, this specification is genuinely multivariate. We find that this classical model performs extremely well at all frequencies, explaining over $70 \%$ of the cross-sectional variation of the returns on these portfolios. Table IV suggests that HML has prices of risk that are highly statistically significant at virtually all frequencies (with the sole exception of the 9 and 10 year horizon). The contribution of the factor loadings associated with SMB and the market is instead reversed. SMB leads to prices of risk which are significant (and positive) at high frequencies but are imprecisely estimated (and, eventually, negative) in the long run. The market returns yield risk prices which follow the opposite pattern. Hence, market risk plays a bigger role in the long run (as testified by the higher value of the static CAPM at lower frequencies).

The interpretation of the Fama-French factors is, to these days, controversial. The relation between Fama-French factors and undiversifiable macro risk has been the subject of some empirical investigation (see, e.g., Liew and Vassalou, 2000, inter alia) but no consensus has emerged. In light of the generally lower pricing errors delivered by the Fama-French model (at least when pricing size- and value-sorted portfolios), the success of recent consumption-based models ${ }^{8}$ should partly be viewed as a by-product of the Fama-French three-factor model being hard to interpret economically. Yet, arguably, this model represents an important benchmark. While, as typically found, we show that all scaled models yield larger pricing errors than the Fama-French model, scaling improves matters drastically.

\section{$7 \quad$ Addressing the critics}

Lewellen and Nagel (2006) and Lewellen et al. (2007) have recently criticized the above two-step approach for testing pricing models on the 25 Fama-French portfolios. They claim that, since

\footnotetext{
${ }^{7}$ The SMB portfolio is the difference between the returns on small firm portfolios and large firm portfolios with the same book-to-market values. The HML portfolio is the difference between the returns on high bookto-market firm portfolios and low book-to-market firm portfolios with the same size. We refer the reader to Kenneth French's web site for details.

${ }^{8}$ The "ultimate consumption" model of Parker and Julliard (2005), for instance, represents a promising alternative to scaled versions of the C-CAPM.
} 
these portfolios have a strong factor structure, the addition of factors, as effectively implied by conditional models, is bound to spuriously inflate the explanatory power of the models being tested. To circumvent this issue, they make two main suggestions: expanding the set of test portfolios beyond the classical 25 Fama-French portfolios and using GLS, rather than OLS, in the second step of the traditional two-pass methodology. These approaches will lead to a more stringent test, but they remain subject to criticisms. For example, even if one takes the view that all assets should be priced by a valid pricing model, it is unclear why portfolios which do not have an obvious factor structure, like the industry portfolios, should provide a more compelling test than the 25 Fama-French portfolios. In a similar vein, GLS reshuffles the original portfolios and prices linear combinations of them, rather than the original portfolios, which are arguably of particular interest.

Table VI contains the same information as in Table III, but instead of reporting adjusted$R^{2}$ s, we report $R^{2}$ values when using GLS in the second step. In the implementation of GLS, we employ the inverse of the unconditional covariance matrix of returns as the weight matrix. The first thing to notice is of course the much lower values of the $R^{2}$ in this environment. Even the Fama-French three-factor model has a GLS $R^{2}$ of $22 \%$ at 1 quarter compared with $73 \%$ for the OLS $R^{2}$. Scaling models by $p m v$ leads to better fit than in the case of the unconditional models. This is true at all horizons. Importantly, no clear pattern across horizons seems to emerge relative to cay. Put it differently, $p m v$ remains competitive under this metric relative to a more sophisticated measure, such as cay.

To increase the universe of portfolios, we add to our original 25 portfolios the 30 industry portfolios ${ }^{9}$. The corresponding results are in Table VII. Once again, we notice that pmv improves the explanatory power of both CAPM and C-CAPM across all horizons, and particularly at business cycle frequencies and in the long run. The usefulness of $p m v$ as a scaling variable relative to cay is apparent when comparing adjusted- $R^{2}$ s.

When examined based on the statistical fit of constructed portfolios (GLS portfolios) or portfolios with a mild factor structure (industry portfolios), well-known scaling variables, such as cay, may perform considerably less well. While the sense in which these portfolios represent a fully compelling test for conditional pricing models may be the object of some debate, $p m v$ continues to fare well as compared to more-involved proxies even under alternative metrics.

In the following section we use economic criteria based on implied conditional betas and conditional risk premia to assess the pricing relevance of $p m v$. We do so in the context of the original 25 Fama-French portfolios.

\footnotetext{
${ }^{9}$ These are also available from Ken French's web site.
} 


\section{Conditional betas and risk premia}

We focus on the C-CAPM. Table VIII reports betas on consumption growth, betas on pmv, as well as betas on the interaction at 4 levels of aggregations, i.e., 2, 3, 4, and 5 years. At all horizons, the average returns on the portfolios behave as described earlier, i.e., they decrease in the size dimension and increase in the value dimension. Lettau and Ludvigson's logic justifies this pattern (Lettau and Ludvigson, 2001b, Section II). In our scaled specification, the correlation between portfolio returns and consumption growth is a function of the scaling factor. In other words, due to the interaction, the partial effect of consumption growth on portfolio returns depends on the scaling variable, i.e., $\bar{\beta}_{t}^{p}=\beta_{\Delta c}^{p}+\beta_{\Delta c, p m v}^{p} p m v_{t-h, t}$. Table VIII reports values of $\bar{\beta}_{t}^{p+}=\beta_{\Delta c}^{p}+\beta_{\Delta c, p m v}^{p} \overline{p m v_{t-h, t}^{+}}$where $\overline{p m v_{t-h, t}^{+}}$is the mean of $p m v$ conditional on it being larger than 1 standard deviation above its mean. We define $\bar{\beta}_{t}^{p-}$ in a similar fashion. These definitions are the same as those in Lettau and Ludvigson (2001b). For small values of $p m v$ the correlation between consumption growth and portfolio returns is generally small and often negative. It is large and positive for large values of $p m v$. Importantly, for large values of $p m v$, the correlation between portfolio returns and consumption growth increases in the value dimension and decreases in the size dimension, often almost monotonically. The spread in the conditional factor loadings is also substantial. Arguably, higher $p m v$ values are associated with worse states of the world. Hence, value stocks require higher excess returns not because their unconditional risk (as measured by their unconditional beta with respect to consumption growth) is higher than for growth stocks. Rather, they appear to require higher excess returns because their conditional risk is higher in bad states (i.e., when $p m v$ is higher).

Lettau and Ludvigson (2001b) use this same logic to justify the role played by cay. Comparing our findings to the pricing ability of cay at the same horizons, in the case of $p m v$ we generally find conditional (on bad states) consumption loadings that align more effectively with historical average portfolio returns, more monotonicity in the conditional (on bad states) loadings, and larger differences in the loadings between small/big firms and low/high book-to-market firms. Consider the 3 year horizon, for instance. Figures 6 and 7 depict these betas conditional on high and low pmv respectively. The low book-to-market/high book-to-market loadings associated with firms in the five size quintiles are $6.7 / 16.6,4.9 / 16.07,2.73 / 13.36,0.16 / 11.51,-4.48 / 8.52$ in the $p m v$ case. They are $4.42 / 4.59,-1.61 / 3.14,-2.78 / 1.53,-2.88 / 5.22,4.73 / 3.84$ in the case of cay. Similar figures occur at alternative horizons (c.f., Table VIII).

It is easy to show that, given conditional consumption loadings equal to $\bar{\beta}_{t}^{p}$, the implied price of consumption risk $\bar{\lambda}_{t}$ can be expressed as $-\widetilde{R}_{t, h} \operatorname{Var}_{t}(\Delta c) c_{2 t}$, where $c_{2 t}=b_{1}+b_{2} p m v_{t-h, t}$. Assuming a constant $\widetilde{R}_{t, h}$ (estimated from the cross-sectional regression) and a constant variance 
of consumption growth, ${ }^{10}$ we evaluate $\bar{\lambda}_{t}$ after estimating the coefficients in $c_{2 t}$ as recommended by Cochrane (1996) and Lettau and Ludvigson (2001b), i.e., using the estimated cross-sectional $\lambda \mathrm{s}$.

\section{Conclusions}

In a world without risk, or with risk-neutral agents, prices are martingales and conditional expectations of future prices only depend on current prices. When risk is meaningful, prices are conditional expectations of future prices only after appropriate stochastic discounting. We conjecture that this stochastic risk correction is correlated with the level of past market variance $(p m v)$. In other words, we conjecture that past financial market variability proxies for more fundamental (and usually difficult to measure) variables that may drive time-variation in the assessment of risk induced by macro factors, such as consumption growth. We test this conjecture by investigating the cross-sectional pricing of classical test assets, namely the Fama-French size- and value-sorted portfolios, using traditional asset pricing models scaled by the level of past market variance. The pricing ability of $p m v$ is found to be substantial, particularly at business-cycle frequencies. When compared to variables that have been shown to be successful in the same classes of models (such as cay), pmv is found to fare very satisfactorily.

\footnotetext{
${ }^{10}$ Both assumptions can be easily relaxed.
} 


\section{References}

[1] Adrian, T. and J. Rosenberg, 2008. Stock returns and volatility: pricing the short-run and long-run components of market risk. Journal of Finance 63, 2997-3030.

[2] Andersen, T.G., Bollerslev, T., Diebold, F.X., Labys, P., 2003. Modeling and forecasting realized volatility. Econometrica 71, 579-625.

[3] Ang, A., Hodrick, R., Xing, Y., Zhang, X., 2006. The cross-section of volatility and expected returns. Journal of Finance 61, 259-299.

[4] Bandi, F.M., Perron, B., 2008. Long-run risk-return trade-offs. Journal of Econometrics 143, 349-374.

[5] Bandi, F.M., Moise, C., Russell, J.R., 2006. The joint pricing of volatility and liquidity. Working paper.

[6] Black, F., 1972. Capital market equilibrium with restricted borrowing. Journal of Business 45, 444-455.

[7] Barndorff-Nielsen, O.E., Shephard, N., 2002. Econometric analysis of realized volatility and its use in estimating stochastic volatility models. Journal of the Royal Statistical Society, Series B 64, 253-280.

[8] Campbell, J.Y., Cochrane, J.H., 1999. By force of habit: A consumption-based explanation of aggregate stock-market behavior. Journal of Political Economy 107, 205-251.

[9] Cochrane, J.H., 1996. A cross-sectional test of an investment-based asset pricing model. Journal of Political Economy 104, 572-621.

[10] Cochrane, J.H., 2004. Asset Pricing. Princeton: Princeton University Press.

[11] Engle, R., Gonzalo, J., 2008. The spline GARCH model for low-frequency volatility and its global macroeconomic causes. Review of Financial Studies 21, 1187-1222.

[12] Fama, E.F., French, K.R., 2002. The cross-section of expected returns. Journal of Finance 47, 427-465.

[13] Fama, E.F., French, K.R., 2003. Common risk factors in the returns on stocks and bonds. Journal of Financial Economics 33, 3-56.

[14] Lettau, M., Ludvigson, S.C., 2001a. Consumption, aggregate wealth, and expected stock returns. Journal of Finance 56, 815-849. 
[15] Lettau, M., Ludvigson, S.C., 2001b. Resurrecting the (C-)CAPM: a cross-sectional test when risk premia are time-varying. Journal of Political Economy 109, 1238-1287.

[16] Lettau, M., Wachter, J., 2007. Why is long-horizon equity less risky? A duration-based explanation of the value premium, Journal of Finance 62, 55-92.

[17] Lewellen, J., Nagel, S., 2006. The conditional CAPM does not explain asset-pricing anomalies. Journal of Financial Economics 82, 289-314.

[18] Lewellen, J., Nagel, S., Shanken, J., 2007. A Skeptical Appraisal of Asset-Pricing Tests. Working paper.

[19] Liew, J., Vassalou, M., 2000. Can book-to-market, size, and momentum be risk factors that predict economic growth? Journal of Financial Economics 57, 221-245.

[20] Moise, C., 2006. Stochastic volatility risk and the size anomaly. Working paper.

[21] Parker, J., Julliard, C. 2005. Consumption risk and the cross-section of expected returns. Journal of Political Economy 113, 185-222.

[22] Santos, T., Veronesi, P., 2006, Labor Income and Predictable Stock Returns. Review of Financial Studies 19, 1-44.

[23] Spiegel, M., Wang, X., 2005. Cross-sectional variation in stock returns: liquidity and idiosyncratic risk. Working paper. 
Table I. Slope of forecasting regressions of market returns and market variance using $p m v$ at different levels of aggregation $h$ in quarters: 1952Q2-2006Q4 (t statistics in parentheses)

\begin{tabular}{|c|c|c|c|c|c|c|c|c|c|c|c|c|}
\hline$h=$ & 1 & 2 & 4 & 8 & 12 & 16 & 20 & 24 & 28 & 32 & 36 & 40 \\
\hline $\begin{array}{l}\text { Market } \\
\text { returns }\end{array}$ & $\begin{array}{r}3.62 \\
(2.43)\end{array}$ & $\begin{array}{r}4.21 \\
(2.39)\end{array}$ & $\begin{array}{r}4.66 \\
(2.76)\end{array}$ & $\begin{array}{r}4.90 \\
(3.25)\end{array}$ & $\begin{array}{r}5.58 \\
(3.08)\end{array}$ & $\begin{array}{r}6.63 \\
(3.40)\end{array}$ & $\begin{array}{r}8.04 \\
(3.38)\end{array}$ & $\begin{array}{r}9.46 \\
(6.53)\end{array}$ & $\begin{array}{r}10.52 \\
(9.77)\end{array}$ & $\begin{array}{c}11.31 \\
(9.23)\end{array}$ & $\begin{array}{r}12.14 \\
(7.81)\end{array}$ & $\begin{array}{r}13.08 \\
(6.88)\end{array}$ \\
\hline Variance & $\begin{array}{r}.22 \\
(2.16)\end{array}$ & $\begin{array}{r}.25 \\
(2.35)\end{array}$ & $\begin{array}{r}.22 \\
(1.20)\end{array}$ & $\begin{array}{r}.11 \\
(.33)\end{array}$ & $\begin{array}{r}.10 \\
(.19)\end{array}$ & $\begin{array}{r}.07 \\
(.14)\end{array}$ & $\begin{array}{r}-.03 \\
(-.04)\end{array}$ & $\begin{array}{r}-.13 \\
(-.13)\end{array}$ & $\begin{array}{r}-.08 \\
(-.13)\end{array}$ & $\begin{array}{r}.07 \\
(.17)\end{array}$ & $\begin{array}{r}.19 \\
(.38)\end{array}$ & $\begin{array}{r}.24 \\
(.46)\end{array}$ \\
\hline$R^{2}$ & 5.0 & 6.2 & 4.9 & 1.3 & 1.0 & .4 & .1 & 1.4 & .5 & .5 & 4.0 & 9.1 \\
\hline
\end{tabular}


Table II. Betas for univariate regressions of the $25 \mathrm{FF}$ portfolio returns on $p m v$ at levels of aggregation $h$ (in quarters) 1952Q2-2006Q4

\begin{tabular}{ll|lllll}
\multicolumn{1}{c}{$h=4$} & \multicolumn{5}{c}{ Size } \\
& & \multicolumn{6}{c}{1} & 2 & 3 & 4 & 5 \\
\cline { 3 - 7 } & 1 & 2.44 & 2.25 & 1.23 & 1.67 & 0.72 \\
& 2 & 3.02 & 2.53 & 1.78 & 1.61 & 1.59 \\
HML & 3 & 3.13 & 1.95 & 1.28 & 1.56 & 0.33 \\
& 4 & 2.92 & 1.70 & 2.05 & 2.74 & 1.02 \\
& 5 & 2.91 & 2.88 & 3.10 & 3.64 & 1.33
\end{tabular}

\begin{tabular}{rr|rlllr}
\multicolumn{1}{c}{$h=12$} & \multicolumn{5}{c}{ Size } \\
& & \multicolumn{1}{c}{1} & 2 & 3 & 4 & \multicolumn{1}{c}{5} \\
\cline { 3 - 7 } & 1 & -1.06 & 0.74 & 0.90 & 0.86 & -1.69 \\
\multirow{4}{*}{ HML } & 2 & 1.55 & 0.42 & 2.01 & 1.35 & 0.02 \\
& 3 & 2.18 & 2.51 & 1.47 & 0.69 & -0.63 \\
& 4 & 2.10 & 2.52 & 1.45 & 1.45 & -0.76 \\
& 5 & 2.61 & 1.21 & 3.03 & 2.40 & 0.09
\end{tabular}

\begin{tabular}{ll|lllll}
$h=20$ & \multicolumn{5}{c}{ Size } \\
& & \multicolumn{6}{c}{1} & 2 & 3 & 4 & 5 \\
\cline { 2 - 7 } & 1 & 1.47 & 6.15 & 7.53 & 6.05 & 1.30 \\
& 2 & 7.05 & 5.83 & 6.94 & 6.40 & 5.62 \\
HML & 3 & 5.97 & 7.47 & 6.52 & 4.45 & 3.11 \\
& 4 & 5.96 & 7.96 & 5.88 & 2.31 & 3.27 \\
& 5 & 8.71 & 5.44 & 8.47 & 5.39 & 5.84
\end{tabular}

\begin{tabular}{ll|rrrrr}
\multicolumn{1}{l}{$h=8$} & \multicolumn{5}{c}{ Size } \\
& & \multicolumn{1}{c}{1} & 2 & 3 & 4 & \multicolumn{1}{c}{5} \\
\cline { 3 - 7 } & 1 & -1.89 & -0.26 & -0.95 & 0.08 & -1.22 \\
& 2 & 0.09 & 0.11 & 0.82 & 0.75 & 0.06 \\
HML & 3 & 1.29 & 1.10 & 0.13 & 0.12 & -0.38 \\
& 4 & 0.80 & 0.86 & 0.22 & 1.35 & -0.81 \\
& 5 & 0.41 & 0.54 & 1.44 & 2.40 & -0.04
\end{tabular}

\begin{tabular}{ll|llllr}
\multicolumn{1}{c}{$h=16$} & \multicolumn{5}{c}{ Size } \\
\cline { 3 - 7 } & & 1 & 2 & 3 & 4 & \multicolumn{1}{c}{5} \\
\hline \multirow{4}{*}{ HML } & 0.68 & 2.74 & 3.57 & 2.36 & -1.86 \\
& 2 & 3.69 & 2.10 & 3.63 & 3.10 & 1.63 \\
& 3 & 3.07 & 4.45 & 3.09 & 1.82 & 0.11 \\
& 4 & 3.31 & 4.03 & 3.12 & 1.29 & 0.14 \\
& 5 & 5.27 & 2.52 & 5.33 & 3.12 & 1.90
\end{tabular}


Table III. Adjusted- $R^{2}(\%)$ from cross-sectional pricing regressions on the 25 FF size- and value-sorted portfolios at different levels of aggregation $h$ (in quarters): 1952Q2-2006Q4

\begin{tabular}{|c|c|c|c|c|c|c|c|c|c|c|c|c|c|}
\hline & & & & & & sines & cycle & & & & & Lon & run \\
\hline & $h=$ & 1 & 2 & 4 & 8 & 12 & 16 & 20 & 24 & 28 & 32 & 36 & 40 \\
\hline Basic mod & & & & & & & & & & & & & \\
\hline & CAPM & -0.7 & -2.2 & -1.8 & 17.5 & 14.7 & -0.7 & -4.3 & 2.4 & 18.0 & 27.8 & 47.5 & 46.6 \\
\hline & C-САРM & 9.0 & 20.4 & 29.2 & 24.7 & 16.2 & 8.6 & -0.9 & -4.3 & -0.6 & 5.3 & 28.4 & 36.0 \\
\hline & FF 3-factor model & 73.0 & 73.7 & 73.3 & 77.2 & 83.7 & 85.6 & 86.0 & 82.4 & 81.2 & 74.9 & 71.7 & 77.1 \\
\hline Scaled mo & & & & & & & & & & & & & \\
\hline With $n m v$ & CAPM & 49.0 & 55.8 & 70.1 & 48.2 & 61.3 & 43.6 & 33.2 & 27.6 & 62.3 & 56.7 & 65.0 & 70.0 \\
\hline & C-CAPM & 4.9 & 13.7 & 66.8 & 55.6 & 70.9 & 69.2 & 54.5 & -4.7 & 5.5 & 38.2 & 69.5 & 74.8 \\
\hline With $c a v$ & CAPM & 40.2 & 28.6 & 23.9 & 39.3 & 50.5 & 65.2 & 77.3 & 70.3 & 32.8 & 60.9 & 54.7 & 55.9 \\
\hline vitur cay & C-СAPM & 53.7 & 44.6 & 49.6 & 46.3 & 35.9 & 33.1 & 37.2 & 37.9 & 1.8 & 14.9 & 35.4 & 49.9 \\
\hline
\end{tabular}


Table IV: Lambdas from cross-sectional pricing regressions on the 25 FF size- and value-sorted portfolios at different levels of aggregation $h$ (in quarters): 1952Q2-2006Q4 (t-statistics in parentheses)

\section{Fama-French 3-factor model}

\begin{tabular}{|c|c|c|c|c|}
\hline$h=$ & constant & market & SMB & HML \\
\hline 1 & $\begin{array}{r}5.06 \\
(3.4)\end{array}$ & $\begin{array}{l}-1.83 \\
(-1.3)\end{array}$ & $\begin{array}{l}0.66 \\
(2.4)\end{array}$ & $\begin{array}{l}1.23 \\
(5.0)\end{array}$ \\
\hline 2 & $\begin{array}{r}5.54 \\
(3.2)\end{array}$ & $\begin{array}{l}-2.25 \\
(-1.3)\end{array}$ & $\begin{array}{l}0.88 \\
(2.6)\end{array}$ & $\begin{array}{l}1.18 \\
(3.9)\end{array}$ \\
\hline 4 & $\begin{array}{r}5.86 \\
(3.1)\end{array}$ & $\begin{array}{l}-2.47 \\
(-1.4)\end{array}$ & $\begin{array}{l}0.67 \\
(2.4)\end{array}$ & $\begin{array}{l}1.70 \\
(6.2)\end{array}$ \\
\hline 8 & $\begin{array}{l}1.97 \\
(1.1)\end{array}$ & $\begin{array}{r}1.33 \\
(.7)\end{array}$ & $\begin{array}{r}0.16 \\
(.7)\end{array}$ & $\begin{array}{l}1.93 \\
(5.1)\end{array}$ \\
\hline 12 & $\begin{array}{l}1.59 \\
(2.3)\end{array}$ & $\begin{array}{r}1.75 \\
(1.8)\end{array}$ & $\begin{array}{l}0.24 \\
(.12)\end{array}$ & $\begin{array}{l}1.81 \\
(4.8)\end{array}$ \\
\hline 16 & $\begin{array}{l}2.23 \\
(2.5)\end{array}$ & $\begin{array}{l}1.31 \\
(1.5)\end{array}$ & $\begin{array}{r}0.15 \\
(.7)\end{array}$ & $\begin{array}{l}2.00 \\
(5.1)\end{array}$ \\
\hline 20 & $\begin{array}{l}2.16 \\
(2.3)\end{array}$ & $\begin{array}{r}1.65 \\
(1.8)\end{array}$ & $\begin{array}{l}0.03 \\
(.12)\end{array}$ & $\begin{array}{l}2.03 \\
(4.8)\end{array}$ \\
\hline 24 & $\begin{array}{l}2.48 \\
(2.4)\end{array}$ & $\begin{array}{r}1.70 \\
(1.7)\end{array}$ & $\begin{array}{r}-0.11 \\
(-.5)\end{array}$ & $\begin{array}{l}2.10 \\
(4.3)\end{array}$ \\
\hline 28 & $\begin{array}{l}2.41 \\
(2.6)\end{array}$ & $\begin{array}{l}2.11 \\
(2.4)\end{array}$ & $\begin{array}{r}-0.15 \\
(-.5)\end{array}$ & $\begin{array}{l}1.82 \\
(3.4)\end{array}$ \\
\hline 32 & $\begin{array}{l}1.84 \\
(1.8)\end{array}$ & $\begin{array}{l}3.09 \\
(3.3)\end{array}$ & $\begin{array}{r}-0.17 \\
(-.5)\end{array}$ & $\begin{array}{l}1.02 \\
(2.0)\end{array}$ \\
\hline 36 & $\begin{array}{r}1.26 \\
(1.1)\end{array}$ & $\begin{array}{l}4.01 \\
(3.7)\end{array}$ & $\begin{array}{r}-0.20 \\
(-.6)\end{array}$ & $\begin{array}{l}0.56 \\
(1.1)\end{array}$ \\
\hline 40 & $\begin{array}{r}1.02 \\
(.9)\end{array}$ & $\begin{array}{l}4.65 \\
(4.7)\end{array}$ & $\begin{array}{r}-0.18 \\
(-.6)\end{array}$ & $\begin{array}{r}0.46 \\
(1.1)\end{array}$ \\
\hline
\end{tabular}




\section{Scaled CAPM}

\begin{tabular}{|c|c|c|c|c|c|c|c|c|}
\hline \multicolumn{5}{|c|}{ Scaled by pmv } & \multicolumn{4}{|c|}{ Scaled by cay } \\
\hline$h=$ & constant & market & pmv & $p m v \times$ market & constant & market & Cay & cay x market \\
\hline 1 & $\begin{array}{r}5.13 \\
(4.2)\end{array}$ & $\begin{array}{l}-1.64 \\
(-1.4)\end{array}$ & $\begin{array}{r}0.71 \\
(2.9)\end{array}$ & $\begin{array}{r}0.43 \\
(.2)\end{array}$ & $\begin{array}{r}5.96 \\
(5.1)\end{array}$ & $\begin{array}{l}-2.35 \\
(-2.2)\end{array}$ & $\begin{array}{l}-2.28 \\
(-3.6)\end{array}$ & $\begin{array}{r}-3.02 \\
(-0.7)\end{array}$ \\
\hline 2 & $\begin{array}{r}2.59 \\
(1.5)\end{array}$ & $\begin{array}{r}0.74 \\
(.5)\end{array}$ & $\begin{array}{c}0.78 \\
4.5)\end{array}$ & $\begin{array}{r}3.12 \\
(1.6)\end{array}$ & $\begin{array}{r}4.97 \\
(3.7)\end{array}$ & $\begin{array}{l}-1.38 \\
(-1.2)\end{array}$ & $\begin{array}{l}-0.98 \\
(-2.1)\end{array}$ & $\begin{array}{r}-0.72 \\
(-.1)\end{array}$ \\
\hline 4 & $\begin{array}{l}3.07 \\
(2.8)\end{array}$ & $\begin{array}{r}0.33 \\
(.3)\end{array}$ & $\begin{array}{l}0.41 \\
(3.3)\end{array}$ & $\begin{array}{r}1.01 \\
(.4)\end{array}$ & $\begin{array}{r}7.36 \\
(3.5)\end{array}$ & $\begin{array}{l}-3.52 \\
(-1.8)\end{array}$ & $\begin{array}{l}-0.68 \\
(-3.1)\end{array}$ & $\begin{array}{l}-6.40 \\
(-1.6)\end{array}$ \\
\hline 8 & $\begin{array}{l}4.45 \\
(1.7)\end{array}$ & $\begin{array}{r}-0.75 \\
(-.3)\end{array}$ & $\begin{array}{r}0.55 \\
(3.4)\end{array}$ & $\begin{array}{r}7.06 \\
(.7)\end{array}$ & $\begin{array}{r}2.37 \\
(.7)\end{array}$ & $\begin{array}{r}1.25 \\
(.4)\end{array}$ & $\begin{array}{l}-0.29 \\
(-3.8)\end{array}$ & $\begin{array}{l}-2.81 \\
(-1.2)\end{array}$ \\
\hline 12 & $\begin{array}{r}4.75 \\
(3.5)\end{array}$ & $\begin{array}{l}-1.37 \\
(-1.0)\end{array}$ & $\begin{array}{l}0.53 \\
(4.6)\end{array}$ & $\begin{array}{r}10.73 \\
(1.1)\end{array}$ & $\begin{array}{r}3.21 \\
(1.7)\end{array}$ & $\begin{array}{r}0.51 \\
(.3)\end{array}$ & $\begin{array}{l}-0.23 \\
(-4.7)\end{array}$ & $\begin{array}{l}-5.03 \\
(-2.7)\end{array}$ \\
\hline 16 & $\begin{array}{l}3.67 \\
(2.7)\end{array}$ & $\begin{array}{r}-0.01 \\
(.0)\end{array}$ & $\begin{array}{l}0.39 \\
(3.4)\end{array}$ & $\begin{array}{r}14.69 \\
(1.2)\end{array}$ & $\begin{array}{l}2.78 \\
(2.3)\end{array}$ & $\begin{array}{r}1.03 \\
(.8)\end{array}$ & $\begin{array}{l}-0.18 \\
(-5.2)\end{array}$ & $\begin{array}{l}-5.43 \\
(-3.4)\end{array}$ \\
\hline 20 & $\begin{array}{l}2.62 \\
(1.5)\end{array}$ & $\begin{array}{r}1.50 \\
(.8)\end{array}$ & $\begin{array}{l}0.28 \\
(2.4)\end{array}$ & $\begin{array}{r}17.52 \\
(1.0)\end{array}$ & $\begin{array}{l}2.73 \\
(2.7)\end{array}$ & $\begin{array}{l}1.25 \\
(1.2)\end{array}$ & $\begin{array}{l}-0.16 \\
(-6.1)\end{array}$ & $\begin{array}{l}-6.98 \\
(-4.4)\end{array}$ \\
\hline 24 & $\begin{array}{r}0.00 \\
(.0)\end{array}$ & $\begin{array}{l}4.39 \\
(1.8)\end{array}$ & $\begin{array}{l}0.14 \\
(1.0)\end{array}$ & $\begin{array}{r}34.61 \\
(1.4)\end{array}$ & $\begin{array}{l}3.52 \\
(2.9)\end{array}$ & $\begin{array}{r}0.58 \\
(.5)\end{array}$ & $\begin{array}{l}-0.15 \\
(-4.4)\end{array}$ & $\begin{array}{l}-6.20 \\
(-2.5)\end{array}$ \\
\hline 28 & $\begin{array}{r}0.00 \\
(.0)\end{array}$ & $\begin{array}{l}4.89 \\
(4.6)\end{array}$ & $\begin{array}{r}-0.05 \\
(-.6)\end{array}$ & $\begin{array}{r}44.44 \\
(2.4)\end{array}$ & $\begin{array}{l}2.10 \\
(1.3)\end{array}$ & $\begin{array}{l}3.01 \\
(1.8)\end{array}$ & $\begin{array}{r}-0.02 \\
(-.4)\end{array}$ & $\begin{array}{l}-4.69 \\
(-1.2)\end{array}$ \\
\hline 32 & $\begin{array}{r}0.37 \\
(.3)\end{array}$ & $\begin{array}{l}4.53 \\
(4.0)\end{array}$ & $\begin{array}{r}0.13 \\
(1.9)\end{array}$ & $\begin{array}{r}67.51 \\
(3.1)\end{array}$ & $\begin{array}{l}1.90 \\
(1.7)\end{array}$ & $\begin{array}{l}3.63 \\
(3.3)\end{array}$ & $\begin{array}{l}0.06 \\
(2.5)\end{array}$ & $\begin{array}{r}-1.70 \\
(-.5)\end{array}$ \\
\hline 36 & $\begin{array}{r}0.76 \\
(.6)\end{array}$ & $\begin{array}{l}4.43 \\
(3.8)\end{array}$ & $\begin{array}{r}0.18 \\
(3.3)\end{array}$ & $\begin{array}{r}79.36 \\
(3.0)\end{array}$ & $\begin{array}{l}1.83 \\
(1.1)\end{array}$ & $\begin{array}{l}4.51 \\
(3.2)\end{array}$ & $\begin{array}{l}0.04 \\
(1.9)\end{array}$ & $\begin{array}{r}-2.39 \\
(-.5)\end{array}$ \\
\hline 40 & $\begin{array}{r}0.86 \\
(.7)\end{array}$ & $\begin{array}{r}4.85 \\
(4.3)\end{array}$ & $\begin{array}{r}0.16 \\
(3.3)\end{array}$ & $\begin{array}{r}92.16 \\
(3.4)\end{array}$ & $\begin{array}{r}2.44 \\
(1.5)\end{array}$ & $\begin{array}{r}4.58 \\
(3.0)\end{array}$ & $\begin{array}{r}0.02 \\
(1.3)\end{array}$ & $\begin{array}{l}-7.52 \\
(-1.4)\end{array}$ \\
\hline
\end{tabular}




\section{Scaled C-CAPM}

\begin{tabular}{|c|c|c|c|c|c|c|c|c|}
\hline & & Scaled by $p n$ & & & & Scaled by $c c$ & & \\
\hline$h=$ & constant & consumption growth & $p m v$ & interaction & constant & consumption growth & cay & interaction \\
\hline 1 & 3.18 & 0.43 & -0.10 & 0.22 & 4.85 & 0.21 & -0.94 & 0.05 \\
\hline & $(5.9)$ & $(2.0)$ & $(-.3)$ & $(.6)$ & $(4.9)$ & $(1.7)$ & $(-1.3)$ & $(.1)$ \\
\hline 2 & 2.70 & 0.25 & 0.06 & 0.26 & 3.93 & 0.24 & -0.29 & 0.03 \\
\hline & (3.7) & (1.3) & $(.2)$ & $(.4)$ & (3.4) & $(2.2)$ & $(-.7)$ & $(.1)$ \\
\hline 4 & 4.29 & -0.02 & 0.15 & -0.41 & 4.78 & 0.27 & -0.34 & -0.44 \\
\hline & (9.6) & $(-.1)$ & $(1.0)$ & $(-1.1)$ & $(4.0)$ & $(2.8)$ & $(-1.7)$ & $(-1.2)$ \\
\hline 8 & 2.81 & 0.26 & 0.47 & 2.80 & 4.63 & 0.20 & -0.20 & -0.41 \\
\hline & (6.8) & $(2.6)$ & (3.0) & (5.5) & (5.4) & (1.7) & $(-2.6)$ & $(-1.3)$ \\
\hline 12 & 2.89 & 0.14 & 0.31 & 2.74 & 5.84 & 0.17 & -0.19 & -0.88 \\
\hline & (11.9) & (1.6) & (2.5) & (6.9) & (8.2) & (1.4) & $(-3.3)$ & $(-2.9)$ \\
\hline 16 & 2.48 & 0.18 & 0.13 & 2.92 & 6.02 & 0.12 & -0.14 & -0.97 \\
\hline & (7.9) & (2.0) & (1.2) & (6.9) & (10.8) & (1.0) & $(-3.4)$ & $(-3.0)$ \\
\hline 20 & 1.35 & 0.15 & 0.26 & 4.25 & 6.88 & 0.02 & -0.14 & -1.37 \\
\hline & (1.9) & (1.5) & (2.6) & (5.6) & (10.8) & (.2) & $(-3.8)$ & $(-2.9)$ \\
\hline 24 & 3.69 & 0.05 & 0.12 & 1.91 & 7.23 & -0.06 & -0.12 & -1.39 \\
\hline & (2.5) & $(.3)$ & (.8) & (1.2) & (7.7) & $(-.6)$ & $(-3.1)$ & $(-2.4)$ \\
\hline 28 & 6.62 & -0.04 & -0.13 & -1.06 & 6.12 & -0.16 & -0.06 & -0.91 \\
\hline & (5.5) & $(-.2)$ & $(-1.0)$ & $(-.8)$ & (5.1) & $(-1.2)$ & $(-1.3)$ & $(-1.2)$ \\
\hline 32 & 5.82 & 0.08 & -0.12 & 1.33 & 3.97 & -0.22 & 0.02 & 0.52 \\
\hline & (6.3) & $(.5)$ & $(-1.4)$ & (.8) & (3.5) & $(-1.7)$ & (.6) & (.8) \\
\hline 36 & 3.94 & 0.09 & 0.05 & 4.45 & 3.07 & -0.34 & 0.00 & 0.21 \\
\hline & (4.6) & $(.7)$ & (1.1) & (2.9) & (2.5) & $(-2.6)$ & (.1) & $(.4)$ \\
\hline 40 & 4.11 & 0.05 & 0.12 & 4.44 & 2.61 & -0.30 & 0.00 & 0.25 \\
\hline 40 & (4.3) & $(.4)$ & (2.8) & (2.9) & $(2.0)$ & $(-2.4)$ & $(.2)$ & $(.5)$ \\
\hline
\end{tabular}


Table V. Forecasting regressions of excess market returns using pmv and cay at different levels of aggregation $h$ in quarters: 1952Q2-2006Q4

\begin{tabular}{|c|c|c|c|c|c|c|c|c|c|c|c|c|}
\hline \multirow[b]{2}{*}{$h=$} & & & & & & & & & & & & \\
\hline & 1 & 2 & 4 & 8 & 12 & 16 & 20 & 24 & 28 & 32 & 36 & 40 \\
\hline$p m v$ & $\begin{array}{c}1.61 \\
(1.77)\end{array}$ & $\begin{array}{c}1.35 \\
(1.29)\end{array}$ & $\begin{array}{c}.82 \\
(.54)\end{array}$ & $\begin{array}{c}.07 \\
(.06)\end{array}$ & $\begin{array}{c}-.48 \\
(-.21)\end{array}$ & $\begin{array}{c}-.39 \\
(-.29)\end{array}$ & $\begin{array}{c}.75 \\
(.69)\end{array}$ & $\begin{array}{c}2.33 \\
(1.86)\end{array}$ & $\begin{array}{c}3.66 \\
(4.15)^{*}\end{array}$ & $\begin{array}{c}4.55 \\
(3.48)^{*}\end{array}$ & $\begin{array}{c}5.80 \\
(4.99)^{*}\end{array}$ & $\begin{array}{c}6.22 \\
(4.76)^{*}\end{array}$ \\
\hline cay & $\begin{array}{c}1.43 \\
(4.21)^{*}\end{array}$ & $\begin{array}{c}2.67 \\
(3.56)^{*}\end{array}$ & $\begin{array}{c}4.83 \\
(3.14)^{*}\end{array}$ & $\begin{array}{c}8.24 \\
(4.01)\end{array}$ & $\begin{array}{c}10.50 \\
(3.00)^{*}\end{array}$ & $\begin{array}{c}11.86 \\
(6.14)^{*}\end{array}$ & $\begin{array}{c}12.87 \\
(6.43)^{*}\end{array}$ & $\begin{array}{c}12.73 \\
(5.01)^{*}\end{array}$ & $\begin{array}{c}9.88 \\
(3.19)^{*}\end{array}$ & $\begin{array}{c}6.88 \\
(1.75)\end{array}$ & $\begin{array}{l}3.19 \\
(.94)\end{array}$ & $\begin{array}{l}1.00 \\
(.28)\end{array}$ \\
\hline
\end{tabular}


Table VI. GLS $\boldsymbol{R}^{2}(\%)$ from cross-sectional pricing regressions on the FF 25 size- and value-sorted portfolios at different horizons: 1952Q2-2006Q4

Weights given by the variance of returns

\begin{tabular}{|c|c|c|c|c|c|c|c|c|c|c|c|c|c|}
\hline & & & & & & ines & cyc & & & & & Lon & run \\
\hline & $h=$ & 1 & 2 & 4 & 8 & 12 & 16 & 20 & 24 & 28 & 32 & 36 & 40 \\
\hline Basic mod & & & & & & & & & & & & & \\
\hline & CAPM & 2.3 & 1.9 & 1.5 & 0.4 & 0.2 & 0.0 & 1.8 & 1.2 & 3.8 & 1.5 & 1.9 & 2.1 \\
\hline & C-СAPM & 1.4 & 0.3 & 2.6 & 2.4 & 3.7 & 0.4 & 1.1 & 1.3 & 1.1 & 1.0 & 0.8 & 1.4 \\
\hline & FF 3-factor model & 21.8 & 17.5 & 10.2 & 4.4 & 4.1 & 4.3 & 9.5 & 7.5 & 8.1 & 8.4 & 6.0 & 5.5 \\
\hline Scaled mo & & & & & & & & & & & & & \\
\hline With nmy & & 4.6 & 4.2 & 9.3 & 1.8 & 1.7 & 0.4 & 2.4 & 4.3 & 14.3 & 8.3 & 3.9 & 2.8 \\
\hline 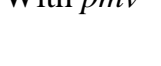 & С-САРМ & 3.6 & 4.1 & 11.2 & 4.4 & 9.3 & 1.3 & 1.9 & 2.1 & 2.2 & 2.0 & 3.3 & 4.0 \\
\hline With cav & CAPM & 3.4 & 2.0 & 5.1 & 3.1 & 5.6 & 9.9 & 11.5 & 7.1 & 4.2 & 1.7 & 2.6 & 3.8 \\
\hline & С-САРМ & 4.7 & 1.5 & 3.5 & 5.0 & 7.4 & 7.5 & 3.1 & 1.9 & 12.2 & 7.5 & 5.5 & 8.5 \\
\hline
\end{tabular}


Table VII. Adjusted- $R^{2}(\%)$ from cross-sectional pricing regressions on the FF 25 size- and value-sorted portfolios and 30 industry portfolios at different horizons: 1952Q2-2006Q4

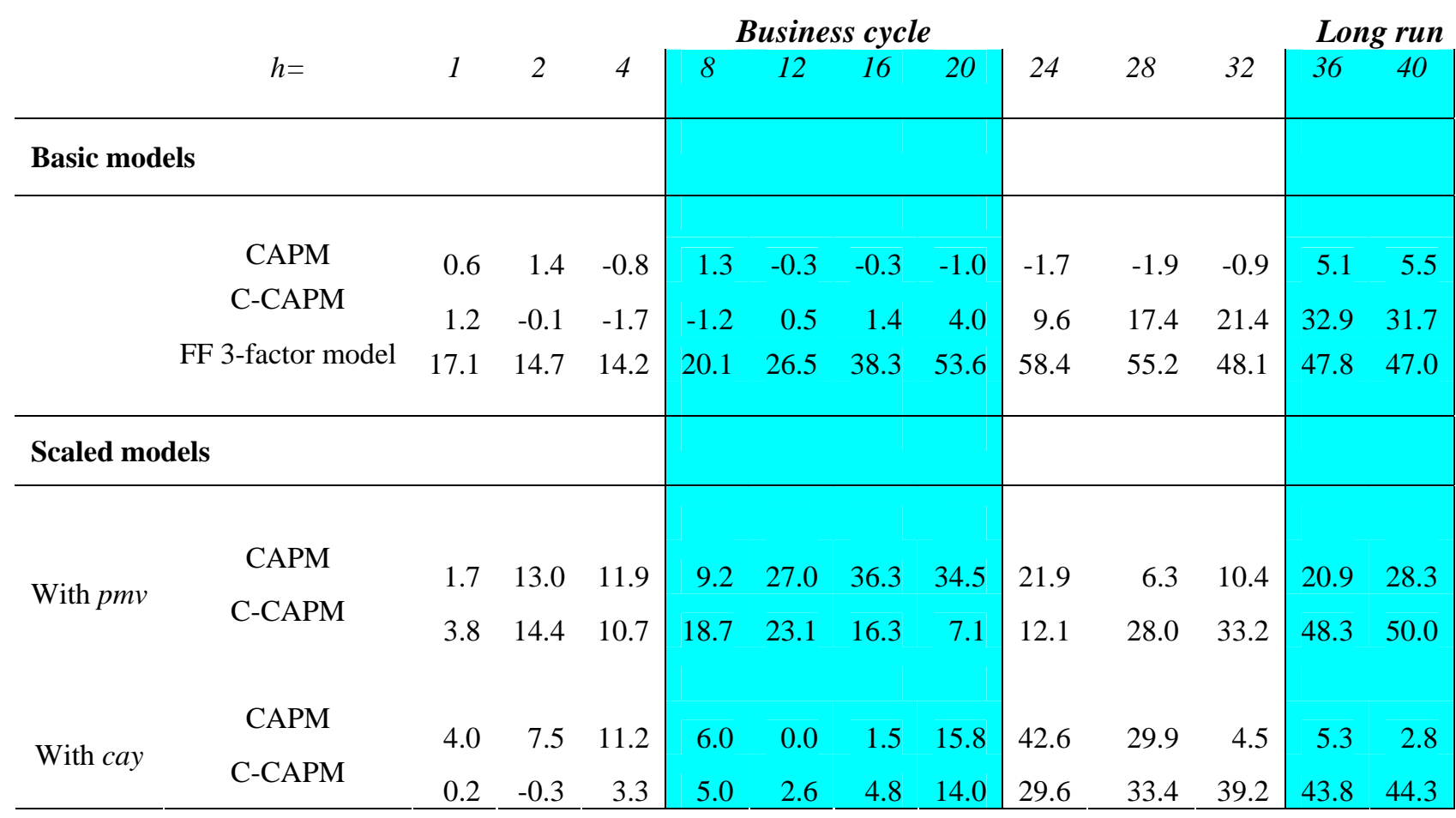


Table VIII: C-CAPM betas and conditional betas (for low and high values of the state variable) with pmv and cay

pmv - 2 year horizon

Betas on consumption growth

\begin{tabular}{|c|c|c|c|c|c|c|}
\hline & & \multicolumn{5}{|c|}{ Size } \\
\hline & \multicolumn{2}{|r|}{1} & 2 & 3 & 4 & 5 \\
\hline & 1 & 2.42 & -2.72 & -0.21 & -0.12 & 4.73 \\
\hline & 2 & 0.04 & -2.73 & -1.80 & -2.58 & -3.48 \\
\hline HML & 3 & -0.96 & 1.56 & -1.22 & -4.24 & -2.08 \\
\hline & 4 & 1.11 & -1.95 & -0.21 & -0.37 & -0.37 \\
\hline & 5 & 0.24 & -2.74 & -2.14 & -0.83 & -1.34 \\
\hline
\end{tabular}

Betas on the interaction

\begin{tabular}{|c|c|c|c|c|c|c|}
\hline & \multicolumn{5}{|c|}{ Size } \\
\hline & & 1 & 2 & 3 & 4 & 5 \\
\hline \multirow{5}{*}{ HML } & 1 & 0.84 & 1.30 & 0.50 & 0.48 & -0.56 \\
\hline & 2 & 1.25 & 1.52 & 1.42 & 1.24 & 1.34 \\
\hline & 3 & 1.30 & 0.83 & 1.37 & 1.95 & 1.25 \\
\hline & 4 & 0.77 & 1.48 & 1.16 & 1.52 & 0.98 \\
\hline & 5 & 1.56 & 2.25 & 1.80 & 1.76 & 1.65 \\
\hline
\end{tabular}

Conditional betas - high pmv

\begin{tabular}{|c|c|c|c|c|c|c|}
\hline & & \multicolumn{5}{|c|}{ Size } \\
\hline & & 1 & 2 & 3 & 4 & 5 \\
\hline & 1 & 9.17 & 7.77 & 3.84 & 3.78 & 0.24 \\
\hline & 2 & 10.12 & 9.55 & 9.62 & 7.44 & 7.30 \\
\hline HML & 3 & 9.56 & 8.22 & 9.84 & 11.47 & 7.96 \\
\hline & 4 & 7.36 & 9.98 & 9.10 & 11.91 & 7.56 \\
\hline & 5 & 12.80 & 15.41 & 12.34 & 13.38 & 11.97 \\
\hline
\end{tabular}

Betas on pmv

\begin{tabular}{cc|lllll}
\multicolumn{1}{c}{} & \multicolumn{6}{c}{ Size } \\
\cline { 3 - 7 } & 1 & 2 & 3 & 4 & 5 \\
\cline { 3 - 7 } HML & -4.71 & -5.02 & -2.74 & -1.63 & 1.02 \\
& 2 & -4.33 & -5.44 & -4.30 & -3.79 & -4.87 \\
& 3 & -3.38 & -1.73 & -4.79 & -7.01 & -4.90 \\
& 4 & -1.88 & -4.48 & -3.88 & -4.06 & -4.31 \\
& 5 & -5.09 & -7.58 & -5.03 & -3.88 & -5.95
\end{tabular}

Conditional betas - low pmv

\begin{tabular}{rr|rrrrr} 
& \multicolumn{6}{c}{ Size } \\
\cline { 3 - 7 } & \multicolumn{1}{l}{} & \multicolumn{1}{c}{2} & \multicolumn{1}{c}{3} & \multicolumn{1}{c}{4} & \multicolumn{1}{c}{5} \\
\cline { 3 - 7 } HML & 3.20 & -1.51 & 0.25 & 0.33 & 4.22 \\
& 2 & 1.20 & -1.32 & -0.49 & -1.43 & -2.24 \\
& 3 & 0.25 & 2.33 & 0.05 & -2.43 & -0.93 \\
& 4 & 1.83 & -0.58 & 0.86 & 1.04 & 0.55 \\
& 5 & 1.69 & -0.65 & -0.47 & 0.80 & 0.19
\end{tabular}




\section{$p m v$ - 3 year horizon}

Betas on consumption growth

\begin{tabular}{rr|rrrrr}
\multicolumn{1}{c}{} & \multicolumn{6}{c}{ Size } \\
\cline { 3 - 7 } & 1 & 2 & 3 & \multicolumn{1}{l}{4} & \multicolumn{1}{c}{5} \\
\hline \multirow{4}{*}{ HML } & 1 & 3.62 & -3.98 & -3.13 & -0.26 & 5.75 \\
& 2 & -3.19 & -7.80 & -4.46 & -6.12 & -5.74 \\
& 3 & -5.46 & -1.06 & -5.65 & -7.60 & -4.36 \\
& 4 & -3.02 & -6.94 & -1.71 & 1.38 & -2.77 \\
& 5 & -4.85 & -6.55 & -5.28 & -1.08 & -2.98
\end{tabular}

Betas on the interaction

\begin{tabular}{cc|lllll}
\multicolumn{1}{c}{} & \multicolumn{6}{c}{ Size } \\
\cline { 3 - 7 } & & & 2 & 3 & 4 & 5 \\
\cline { 3 - 7 } HML & 0.29 & 0.84 & 0.55 & 0.04 & -0.97 \\
& 2 & 1.21 & 1.76 & 1.33 & 1.26 & 0.99 \\
& 3 & 1.63 & 1.04 & 1.64 & 1.71 & 0.97 \\
& 4 & 1.23 & 2.00 & 0.92 & 0.67 & 0.82 \\
& 5 & 2.04 & 2.14 & 1.76 & 1.19 & 1.09
\end{tabular}

Conditional betas $-p m v$ high

\begin{tabular}{rl|rrrrr}
\multicolumn{1}{r}{} & \multicolumn{6}{c}{ Size } \\
\cline { 3 - 7 } & & \multicolumn{1}{c}{2} & 3 & \multicolumn{1}{c}{4} & \multicolumn{1}{c}{5} \\
\cline { 3 - 7 } HML & 6.71 & 4.91 & 2.73 & 0.16 & -4.48 \\
& 2 & 9.60 & 10.75 & 9.60 & 7.19 & 4.72 \\
& 3 & 11.78 & 9.90 & 11.63 & 10.45 & 5.90 \\
& 4 & 10.02 & 14.21 & 8.04 & 8.43 & 5.91 \\
& 5 & 16.68 & 16.07 & 13.36 & 11.51 & 8.52
\end{tabular}

Betas on pmv

\begin{tabular}{rllllll}
\multicolumn{1}{c}{} & \multicolumn{6}{c}{ Size } \\
\cline { 3 - 7 } & & & 2 & 3 & \multicolumn{1}{c}{4} & \multicolumn{1}{c}{5} \\
\cline { 3 - 7 } HML & 1 & -1.31 & -3.44 & -1.98 & 0.65 & 3.40 \\
& 2 & -3.86 & -8.17 & -4.16 & -4.94 & -5.15 \\
& 3 & -5.38 & -1.71 & -6.15 & -7.68 & -5.39 \\
& 4 & -3.34 & -6.81 & -2.49 & -0.77 & -4.57 \\
& 5 & -6.36 & -8.56 & -5.00 & -2.42 & -4.80
\end{tabular}

Conditional betas - pmv low

\begin{tabular}{|c|c|c|c|c|c|c|}
\hline & \multirow{2}{*}{\multicolumn{2}{|c|}{1}} & & & & \\
\hline & & & 2 & 3 & 4 & 5 \\
\hline & 1 & 4.18 & -2.36 & -2.06 & -0.18 & 3.88 \\
\hline & 2 & -0.86 & -4.42 & -1.90 & -3.69 & -3.83 \\
\hline HML & 3 & -2.31 & 0.94 & -2.50 & -4.31 & -2.48 \\
\hline & 4 & -0.64 & -3.08 & 0.07 & 2.67 & -1.18 \\
\hline & 5 & -0.93 & -2.42 & -1.88 & 1.22 & -0.88 \\
\hline
\end{tabular}




\section{pmv - 4 year horizon}

Betas on consumption growth

\begin{tabular}{|c|c|c|c|c|c|c|}
\hline & & \multicolumn{5}{|c|}{ Size } \\
\hline & & 1 & 2 & 3 & 4 & 5 \\
\hline & 1 & 9.48 & -2.53 & -3.21 & 0.01 & 2.24 \\
\hline & 2 & -1.82 & -9.47 & -5.63 & -7.81 & -10.10 \\
\hline HML & 3 & -7.50 & -2.02 & -6.86 & -10.28 & -8.37 \\
\hline & 4 & -4.24 & -10.51 & -3.43 & 0.35 & -6.22 \\
\hline & 5 & -3.69 & -6.86 & -5.34 & -3.52 & -5.31 \\
\hline
\end{tabular}

Betas on interaction

\begin{tabular}{|c|c|c|c|c|c|c|}
\hline & & \multicolumn{5}{|c|}{ Size } \\
\hline & & 1 & 2 & 3 & 4 & 5 \\
\hline & 1 & -0.32 & 0.45 & 0.51 & -0.02 & -0.29 \\
\hline & 2 & 0.84 & 1.62 & 1.31 & 1.29 & 1.52 \\
\hline [ML & 3 & 1.62 & 1.28 & 1.58 & 1.81 & 1.36 \\
\hline & 4 & 1.30 & 2.30 & 1.27 & 0.84 & 1.24 \\
\hline & 5 & 1.72 & 1.81 & 1.61 & 1.52 & 1.27 \\
\hline
\end{tabular}

Conditional betas - pmv high

\begin{tabular}{rr|rrrrr}
\multicolumn{1}{r}{} & \multicolumn{6}{c}{ Size } \\
\cline { 3 - 7 } & & \multicolumn{1}{c}{2} & \multicolumn{1}{c}{3} & \multicolumn{1}{c}{4} \\
\hline \multirow{3}{*}{ HML } & 1 & 5.31 & 3.19 & 3.30 & -0.29 & -1.47 \\
& 2 & 8.92 & 11.37 & 11.21 & 8.71 & 9.38 \\
& 3 & 13.25 & 14.34 & 13.44 & 12.91 & 9.06 \\
& 4 & 12.47 & 19.01 & 12.90 & 11.12 & 9.74 \\
& 5 & 18.41 & 16.35 & 15.27 & 16.04 & 11.00
\end{tabular}

Betas on pmv

\begin{tabular}{rrrrrrr}
\multicolumn{1}{r}{} & \multicolumn{6}{c}{ Size } \\
\cline { 3 - 7 } & & \multicolumn{1}{c}{2} & \multicolumn{3}{c}{3} & \multicolumn{1}{c}{4} \\
\cline { 3 - 7 } HML & 6.09 & -0.21 & 0.07 & 2.47 & 0.31 \\
& 2 & -0.60 & -8.76 & -4.29 & -5.64 & -9.05 \\
& 3 & -6.93 & -1.77 & -6.47 & -10.15 & -9.17 \\
& 4 & -3.97 & -10.11 & -3.68 & -2.08 & -7.73 \\
& 5 & -3.53 & -8.01 & -3.69 & -4.78 & -5.71
\end{tabular}

Conditional betas - pmv low

Size

\begin{tabular}{rr|rrrrr}
\multicolumn{1}{c}{} & \multicolumn{1}{l}{1} & \multicolumn{1}{l}{2} & \multicolumn{1}{l}{3} & \multicolumn{1}{l}{4} & \multicolumn{1}{c}{5} \\
\cline { 2 - 7 } HML & 1 & 8.50 & -1.19 & -1.69 & -0.06 & 1.37 \\
& 2 & 0.69 & -4.60 & -1.70 & -3.95 & -5.55 \\
& 3 & -2.65 & 1.80 & -2.11 & -4.86 & -4.30 \\
& 4 & -0.34 & -3.61 & 0.39 & 2.87 & -2.49 \\
& 5 & 1.48 & -1.44 & -0.52 & 1.05 & -1.50
\end{tabular}




\section{pmv - 5 year horizon}

Betas on consumption growth

\begin{tabular}{rrrrrrr} 
& \multicolumn{6}{c}{ Size } \\
\cline { 3 - 7 } & \multicolumn{1}{c}{1} & \multicolumn{1}{c}{2} & \multicolumn{1}{c}{3} & \multicolumn{1}{c}{5} \\
\cline { 3 - 7 } HML & 16.12 & 3.45 & 2.15 & 2.21 & -1.09 \\
& 2 & 4.66 & -5.36 & -2.28 & -6.85 & -12.56 \\
& 3 & -4.14 & 3.30 & -2.47 & -8.79 & -9.36 \\
& 4 & -0.20 & -6.85 & 0.29 & 0.86 & -7.57 \\
& 5 & 5.07 & -0.52 & -2.83 & -5.13 & -5.07
\end{tabular}

Betas on interaction

\begin{tabular}{rr|rrrrr}
\multicolumn{1}{r|}{} & \multicolumn{6}{c}{ Size } \\
\cline { 3 - 7 } & \multicolumn{1}{|c}{} & \multicolumn{1}{c}{2} & 3 & \multicolumn{1}{l}{4} & 5 \\
\hline \multirow{4}{*}{ HML } & 1 & -0.85 & -0.13 & 0.04 & -0.01 & 0.47 \\
& 2 & 0.00 & 1.03 & 0.89 & 1.17 & 1.83 \\
& 3 & 0.93 & 0.75 & 0.95 & 1.49 & 1.47 \\
& 4 & 0.69 & 1.66 & 1.00 & 0.86 & 1.41 \\
& 5 & 0.57 & 0.90 & 1.17 & 1.73 & 1.32
\end{tabular}

Conditional betas - pmv high

\begin{tabular}{|c|c|c|c|c|c|c|}
\hline & & \multicolumn{5}{|c|}{ Size } \\
\hline & \multicolumn{2}{|r|}{1} & 2 & 3 & 4 & 5 \\
\hline & 1 & 3.19 & 1.53 & 2.69 & 2.11 & 5.99 \\
\hline & 2 & 4.73 & 10.20 & 11.15 & 10.88 & 15.14 \\
\hline HML & 3 & 9.99 & 14.62 & 11.88 & 13.83 & 12.88 \\
\hline & 4 & 10.18 & 18.35 & 15.45 & 13.85 & 13.79 \\
\hline & 5 & 13.67 & 13.09 & 14.95 & 21.11 & 14.98 \\
\hline
\end{tabular}

Beta on pmv

\begin{tabular}{rr|rrlll} 
& \multicolumn{6}{c}{ Size } \\
\cline { 3 - 7 } & & \multicolumn{1}{c}{2} & 3 & \multicolumn{1}{l}{4} & \multicolumn{1}{l}{5} \\
\cline { 3 - 7 } HML & 14.76 & 8.76 & 8.66 & 7.40 & -1.35 \\
& 2 & 9.82 & -1.77 & 1.78 & -2.70 & -9.71 \\
& 3 & -0.49 & 6.25 & 1.00 & -7.20 & -8.77 \\
& 4 & 2.90 & -3.26 & 1.76 & -0.84 & -7.29 \\
& 5 & 9.32 & 1.29 & 1.75 & -5.09 & -2.85
\end{tabular}

Conditional betas $-p m v$ low

\begin{tabular}{rrrrrrr} 
& \multicolumn{6}{c}{ Size } \\
\cline { 3 - 7 } & \multicolumn{1}{c}{1} & \multicolumn{1}{c}{2} & 3 & \multicolumn{1}{l}{4} & \multicolumn{1}{c}{5} \\
\cline { 3 - 7 } HML & 12.70 & 2.94 & 2.29 & 2.19 & 0.78 \\
& 2 & 4.68 & -1.25 & 1.27 & -2.16 & -5.23 \\
& 3 & -0.40 & 6.30 & 1.33 & -2.81 & -3.48 \\
& 4 & 2.54 & -0.18 & 4.30 & 4.30 & -1.92 \\
& 5 & 7.34 & 3.08 & 1.87 & 1.81 & 0.23
\end{tabular}




\section{cay - 2 year horizon}

Betas on consumption growth

\begin{tabular}{cc|lllll}
\multicolumn{1}{c}{} & \multicolumn{6}{c}{ Size } \\
\cline { 3 - 7 } & & & 2 & 3 & 4 & 5 \\
\cline { 3 - 7 } HML & 5.88 & 2.17 & 2.27 & 1.82 & 4.00 \\
& 2 & 4.62 & 2.80 & 3.51 & 2.29 & 1.96 \\
& 3 & 3.70 & 4.86 & 4.08 & 2.90 & 2.94 \\
& 4 & 4.22 & 3.75 & 4.38 & 5.19 & 3.96 \\
& 5 & 6.21 & 5.39 & 4.26 & 5.60 & 5.27
\end{tabular}

Betas on the interaction

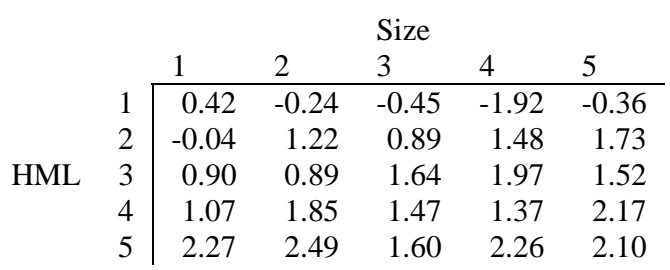

Conditional betas - cay high

\begin{tabular}{rr|rrrrr}
\multicolumn{1}{r}{} & \multicolumn{6}{c}{ Size } \\
\cline { 3 - 7 } & & \multicolumn{1}{c}{2} & 3 & \multicolumn{1}{c}{4} & 5 \\
\hline \multirow{3}{*}{ HML } & 1 & 6.76 & 1.68 & 1.33 & -2.16 & 3.25 \\
& 2 & 4.54 & 5.32 & 5.35 & 5.36 & 5.53 \\
& 3 & 5.56 & 6.70 & 7.47 & 6.98 & 6.10 \\
& 4 & 6.43 & 7.58 & 7.43 & 8.03 & 8.46 \\
& 5 & 10.91 & 10.56 & 7.58 & 10.28 & 9.62
\end{tabular}

Betas on cay

\begin{tabular}{rr|rrrrr}
\multicolumn{1}{r}{} & \multicolumn{6}{c}{ Size } \\
\cline { 3 - 7 } & & \multicolumn{1}{c}{2} & \multicolumn{1}{c}{3} & \multicolumn{1}{c}{4} & \multicolumn{1}{c}{5} \\
\cline { 3 - 7 } HML & 5.73 & 10.09 & 12.40 & 15.56 & 14.04 \\
& 2 & 7.64 & 1.61 & 5.59 & 3.72 & 4.87 \\
& 3 & 2.43 & 4.46 & 2.52 & 0.36 & 4.09 \\
& 4 & 2.86 & 2.58 & 3.26 & 2.42 & 1.98 \\
& 5 & 0.18 & -1.68 & 0.73 & -0.16 & 4.93
\end{tabular}

Conditional betas - cay low

\begin{tabular}{rr|lllrr}
\multicolumn{1}{r|}{} & \multicolumn{6}{c}{ Size } \\
\cline { 3 - 7 } & & & 2 & 3 & \multicolumn{1}{c}{4} & \multicolumn{1}{c}{5} \\
\cline { 3 - 7 } HML & 5.05 & 2.65 & 3.16 & 5.63 & 4.72 \\
& 2 & 4.70 & 0.39 & 1.74 & -0.64 & -1.47 \\
& 3 & 1.92 & 3.09 & 0.83 & -1.02 & -0.09 \\
& 4 & 2.10 & 0.07 & 1.45 & 2.47 & -0.35 \\
& 5 & 1.70 & 0.44 & 1.08 & 1.11 & 1.10
\end{tabular}




\section{cay - 3 years horizon}

Beta on consumption growth

\begin{tabular}{rl|llllr}
\multicolumn{1}{r|}{} & \multicolumn{6}{c}{ Size } \\
\cline { 3 - 7 } & & 1 & 2 & 3 & 4 & \multicolumn{1}{c}{5} \\
\cline { 3 - 7 } HML & 5.50 & 0.48 & 0.13 & 0.54 & 2.72 \\
& 2 & 2.42 & 0.68 & 1.71 & 0.01 & -0.23 \\
& 3 & 1.72 & 3.36 & 2.01 & 0.62 & 1.08 \\
& 4 & 2.31 & 2.14 & 2.54 & 4.22 & 1.92 \\
& 5 & 4.08 & 3.31 & 2.30 & 3.90 & 2.92
\end{tabular}

Betas on the interaction

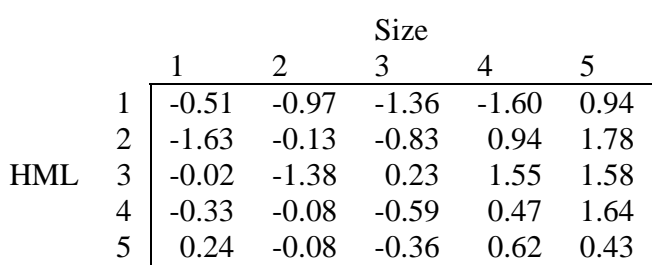

Conditional betas - cay high

\begin{tabular}{rr|rrrrr}
\multicolumn{1}{r}{} & \multicolumn{6}{c}{ Size } \\
\cline { 3 - 7 } & 1 & \multicolumn{1}{c}{2} & \multicolumn{1}{l}{3} & \multicolumn{1}{l}{4} & 5 \\
\hline \multirow{4}{*}{ HML } & 1 & 4.42 & -1.61 & -2.78 & -2.88 & 4.73 \\
& 2 & -1.07 & 0.40 & -0.06 & 2.02 & 3.58 \\
& 3 & 1.69 & 0.41 & 2.50 & 3.94 & 4.47 \\
& 4 & 1.60 & 1.96 & 1.28 & 5.22 & 5.43 \\
& 5 & 4.59 & 3.14 & 1.53 & 5.22 & 3.84
\end{tabular}

Betas on cay

\begin{tabular}{rrrrrrr} 
& \multicolumn{6}{c}{ Size } \\
\cline { 3 - 7 } & & \multicolumn{1}{c}{1} & \multicolumn{1}{c}{3} & \multicolumn{1}{c}{4} & \multicolumn{1}{c}{5} \\
\cline { 3 - 7 } HML & 11.43 & 16.46 & 20.87 & 21.63 & 13.98 \\
& 2 & 17.10 & 7.15 & 15.01 & 6.21 & 5.38 \\
& 3 & 6.12 & 16.28 & 8.88 & 0.56 & 4.74 \\
& 4 & 8.15 & 11.25 & 12.04 & 6.38 & 4.12 \\
& 5 & 7.96 & 7.70 & 9.34 & 5.25 & 14.26
\end{tabular}

Conditional betas - cay low

\begin{tabular}{|c|c|c|c|c|c|c|}
\hline & & \multicolumn{5}{|c|}{ Size } \\
\hline & & 1 & 2 & 3 & 4 & 5 \\
\hline & 1 & 6.53 & 2.45 & 2.88 & 3.77 & 0.82 \\
\hline & 2 & 5.72 & 0.93 & 3.37 & -1.90 & -3.82 \\
\hline HML & 3 & 1.75 & 6.14 & 1.54 & -2.52 & -2.12 \\
\hline & 4 & 2.98 & 2.31 & 3.73 & 3.28 & -1.39 \\
\hline & 5 & 3.60 & 3.46 & 3.03 & 2.65 & 2.05 \\
\hline
\end{tabular}




\section{cay - 4 year horizon}

Betas on consumption growth

\begin{tabular}{rr|rrrrr}
\multicolumn{1}{r}{} & \multicolumn{6}{c}{ Size } \\
\cline { 3 - 7 } & & \multicolumn{1}{c}{2} & \multicolumn{1}{l}{3} & \multicolumn{1}{l}{4} & \multicolumn{1}{c}{5} \\
\hline \multirow{4}{*}{ HML } & 1 & -13 & -0.56 & -0.91 & -0.39 & 2.20 \\
& 2 & 1.33 & -0.53 & 0.68 & -1.24 & -0.99 \\
& 3 & 0.33 & 3.08 & 1.14 & -0.31 & 0.11 \\
& 4 & 1.36 & 1.28 & 2.36 & 3.91 & 1.42 \\
& 5 & 3.18 & 2.29 & 1.38 & 3.32 & 1.97
\end{tabular}

Betas on the interaction

\begin{tabular}{|c|c|c|c|c|c|c|}
\hline & \multicolumn{5}{|c|}{ Size } \\
\hline & & 1 & 2 & 3 & 4 & 5 \\
\hline & 1 & -0.49 & -0.77 & -1.73 & -0.87 & 1.22 \\
\hline & 2 & -0.95 & 0.38 & -0.89 & 1.79 & 1.72 \\
\hline HML & 3 & 1.47 & -1.95 & -0.04 & 2.08 & 2.46 \\
\hline & 4 & 0.82 & -0.57 & -0.87 & 1.34 & 1.61 \\
\hline & 5 & -0.13 & 0.15 & -0.64 & 0.75 & -0.55 \\
\hline
\end{tabular}

Conditional betas - cay high

\begin{tabular}{rr|rrrrr}
\multicolumn{1}{r}{} & \multicolumn{6}{c}{ Size } \\
\cline { 3 - 7 } & 1 & \multicolumn{1}{c}{2} & \multicolumn{1}{c}{3} & \multicolumn{1}{l}{4} & 5 \\
\hline \multirow{4}{*}{ HML } & 1 & 5.06 & -2.25 & -4.69 & -2.31 & 4.86 \\
& 2 & -0.74 & 0.30 & -1.28 & 2.68 & 2.78 \\
& 3 & 3.54 & -1.19 & 1.05 & 4.25 & 5.51 \\
& 4 & 3.16 & 0.04 & 0.46 & 6.83 & 4.93 \\
& 5 & 2.90 & 2.63 & -0.03 & 4.96 & 0.76
\end{tabular}

Betas on cay

\begin{tabular}{rr|rrllr} 
& \multicolumn{7}{c}{ Size } \\
\cline { 3 - 7 } & & \multicolumn{1}{c}{2} & 3 & \multicolumn{1}{l}{4} & \multicolumn{1}{c}{5} \\
\cline { 3 - 7 } HML & 12.43 & 17.36 & 27.73 & 22.73 & 16.64 \\
& 2 & 15.81 & 3.87 & 17.37 & -0.10 & 6.36 \\
& 3 & -5.27 & 23.45 & 11.49 & -5.98 & -1.91 \\
& 4 & -1.36 & 14.74 & 14.28 & -0.10 & 4.96 \\
& 5 & 9.01 & 5.97 & 13.35 & 4.14 & 25.63
\end{tabular}

Conditional betas - cay low

\begin{tabular}{rrrrrrr} 
& \multicolumn{6}{c}{ Size } \\
\cline { 3 - 7 } & & \multicolumn{1}{c}{1} & \multicolumn{1}{c}{2} & 3 & \multicolumn{1}{l}{4} & \multicolumn{1}{c}{5} \\
\cline { 2 - 7 } HML & 7.12 & 1.00 & 2.56 & 1.37 & -0.25 \\
& 2 & 3.24 & -1.29 & 2.48 & -4.84 & -4.45 \\
& 3 & -2.63 & 7.00 & 1.22 & -4.51 & -4.85 \\
& 4 & -0.29 & 2.42 & 4.11 & 1.21 & -1.82 \\
& 5 & 3.43 & 1.98 & 2.68 & 1.81 & 3.09
\end{tabular}




\section{cay - 5 year horizon}

Betas on consumption growth

\begin{tabular}{|c|c|c|c|c|c|c|}
\hline & & \multicolumn{5}{|c|}{ Size } \\
\hline & \multicolumn{2}{|r|}{1} & 2 & 3 & 4 & 5 \\
\hline & 1 & 5.68 & -1.08 & -1.48 & -0.89 & 2.24 \\
\hline & 2 & -0.62 & -1.81 & -0.62 & -2.16 & -1.74 \\
\hline HML & 3 & -2.08 & 2.17 & -0.25 & -1.09 & -0.29 \\
\hline & 4 & -0.53 & -0.67 & 2.17 & 3.52 & 0.66 \\
\hline & 5 & 1.18 & 0.95 & -0.67 & 2.06 & 1.21 \\
\hline
\end{tabular}

Betas on the interaction

\begin{tabular}{rr|rrrrr}
\multicolumn{1}{r}{} & \multicolumn{6}{c}{ Size } \\
\cline { 3 - 7 } & 1 & \multicolumn{1}{c}{2} & \multicolumn{1}{c}{3} & \multicolumn{1}{c}{4} & \multicolumn{1}{c}{5} \\
\cline { 3 - 7 } HML & 2.59 & -0.10 & -1.55 & -0.30 & 0.58 \\
& 2 & 1.24 & 1.49 & 0.12 & 1.99 & 0.73 \\
& 3 & 3.61 & -0.69 & 0.38 & 2.08 & 1.78 \\
& 4 & 3.02 & 0.58 & -0.49 & 1.95 & 0.95 \\
& 5 & 1.70 & 1.17 & 0.32 & 1.65 & -1.57
\end{tabular}

Conditional betas - cay high

\begin{tabular}{rr|rrrrr}
\multicolumn{1}{r}{} & \multicolumn{6}{c}{ Size } \\
\cline { 3 - 7 } & 1 & \multicolumn{1}{c}{2} & \multicolumn{1}{l}{3} & \multicolumn{1}{c}{4} & \multicolumn{1}{c}{5} \\
\hline \multirow{4}{*}{ HML } & 11.42 & -1.31 & -4.92 & -1.56 & 3.54 \\
& 2 & 2.14 & 1.48 & -0.36 & 2.26 & -0.12 \\
& 3 & 5.93 & 0.64 & 0.60 & 3.53 & 3.65 \\
& 4 & 6.18 & 0.60 & 1.08 & 7.84 & 2.78 \\
& 5 & 4.95 & 3.55 & 0.04 & 5.72 & -2.27
\end{tabular}

Betas on cay

\begin{tabular}{rrrrrrr}
\multicolumn{1}{r}{} & \multicolumn{6}{c}{ Size } \\
\cline { 3 - 7 } & 1 & \multicolumn{1}{c}{2} & \multicolumn{1}{c}{3} & \multicolumn{1}{c}{4} & \multicolumn{1}{c}{5} \\
\cline { 3 - 7 } HML & -14.58 & 16.17 & 33.87 & 25.17 & 27.82 \\
& 2 & -1.04 & -6.14 & 10.98 & -3.14 & 16.15 \\
& 3 & -29.01 & 16.74 & 9.07 & -10.09 & 2.96 \\
& 4 & -23.10 & 4.30 & 12.98 & -7.56 & 10.54 \\
& 5 & -8.46 & -5.33 & 5.58 & -5.43 & 40.31
\end{tabular}

Conditional betas - cay low

\begin{tabular}{rr|rrrrr} 
& \multicolumn{6}{c}{ Size } \\
\cline { 3 - 7 } & & \multicolumn{1}{c}{2} & \multicolumn{1}{c}{3} & \multicolumn{1}{c}{4} & \multicolumn{1}{c}{5} \\
\cline { 3 - 7 } HML & 0.41 & -0.87 & 1.69 & -0.29 & 1.05 \\
& 2 & -3.16 & -4.84 & -0.86 & -6.23 & -3.23 \\
& 3 & -9.44 & 3.57 & -1.02 & -5.34 & -3.92 \\
& 4 & -6.69 & -1.85 & 3.17 & -0.44 & -1.28 \\
& 5 & -2.28 & -1.45 & -1.33 & -1.31 & 4.40
\end{tabular}


Figure 1. Adjusted R2 in cross-sectional regression

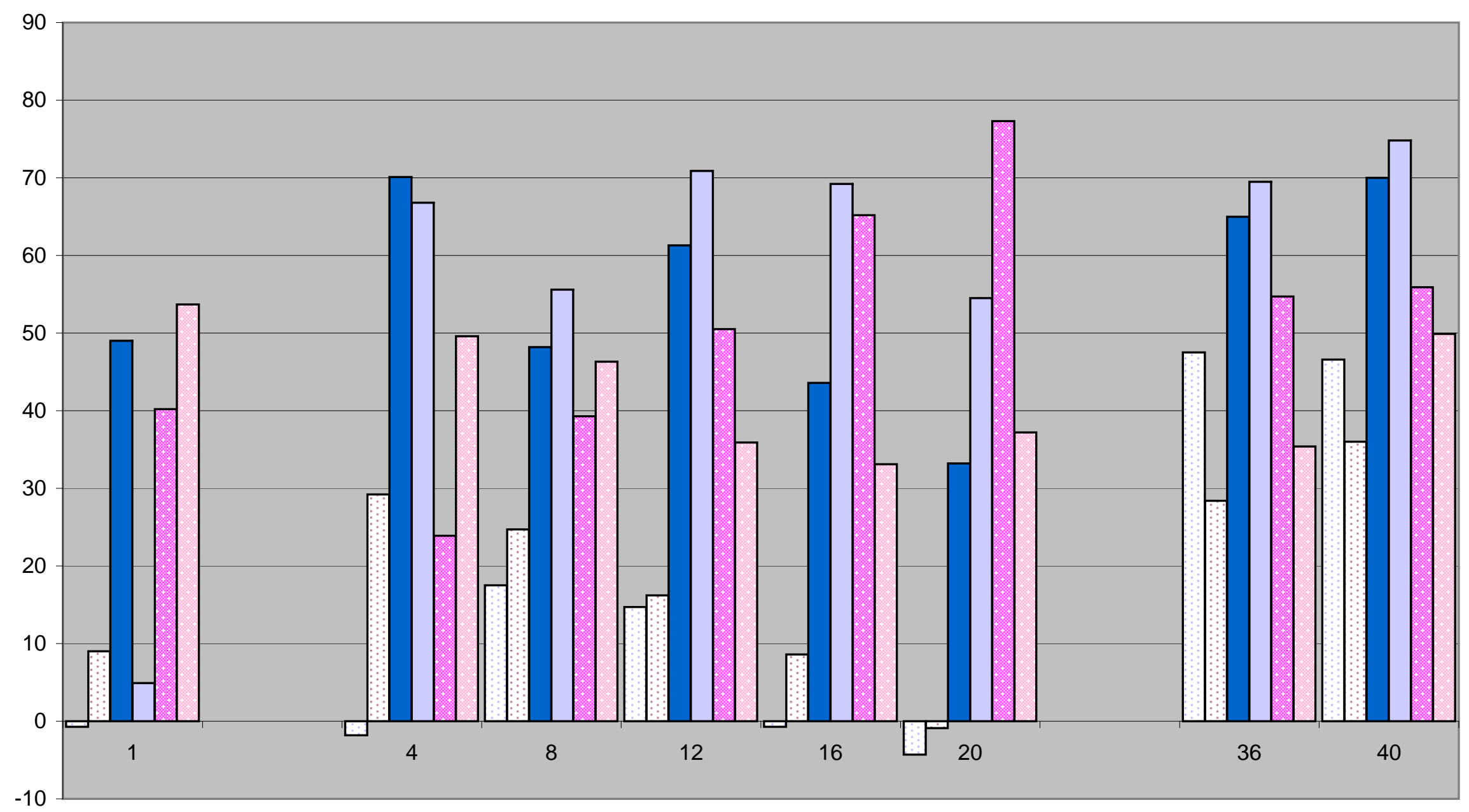

Horizon (in quarters)

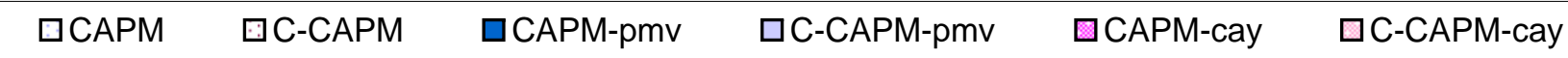


Figure 2. Realized vs. fitted returns on FF portfolios - CAPM
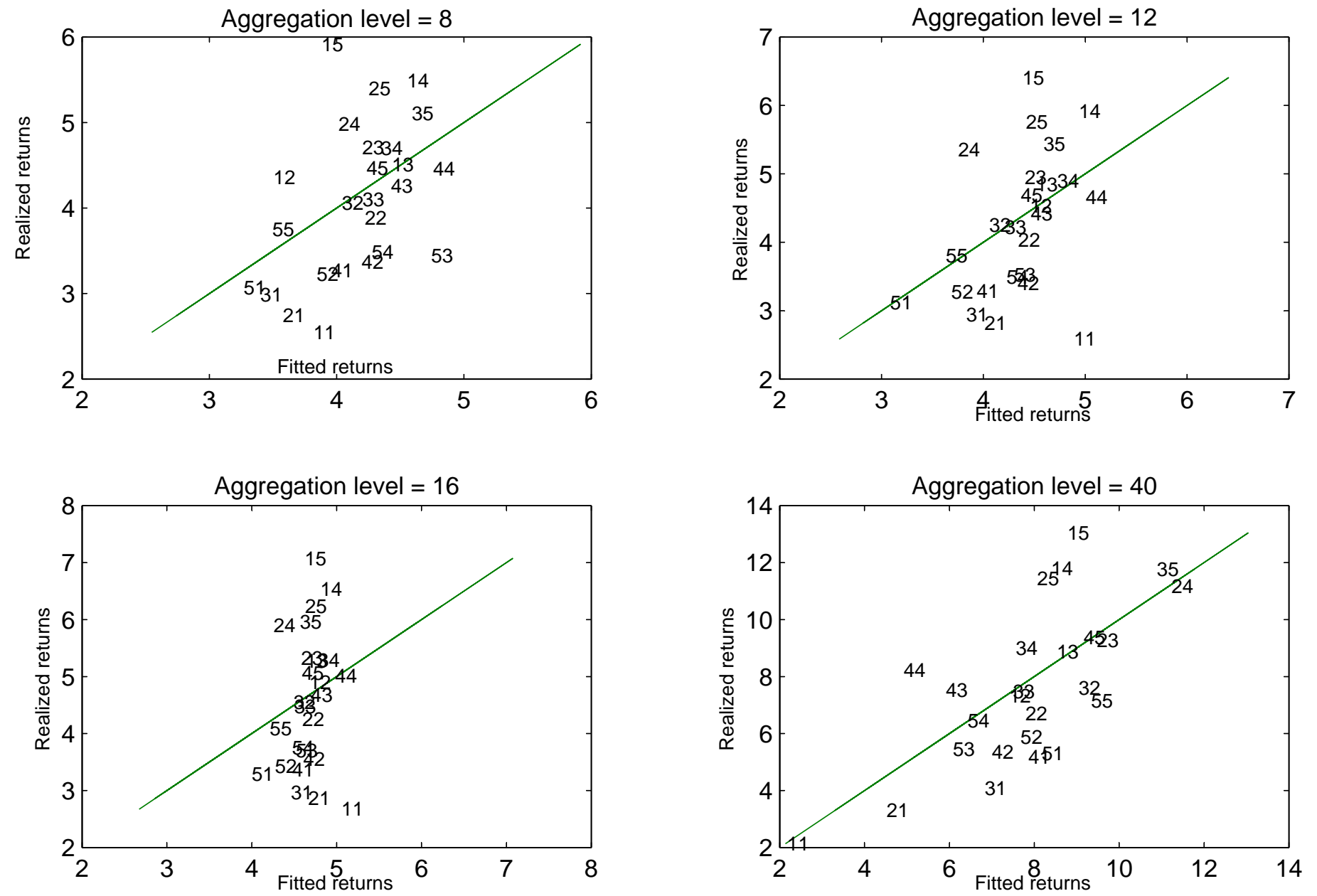
Figure 3. Realized vs. fitted returns on FF portfolios - CAPM scaled by pmv

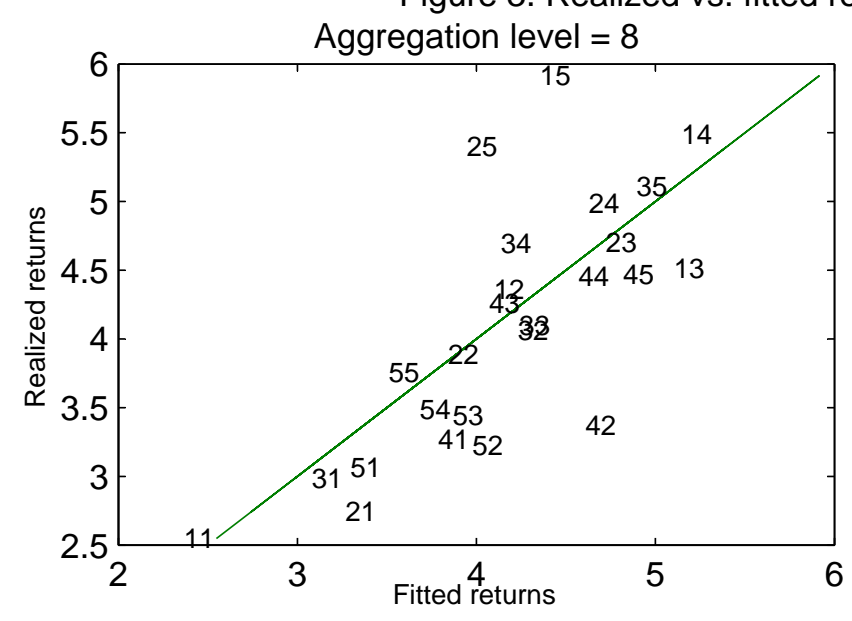

Aggregation level $=12$
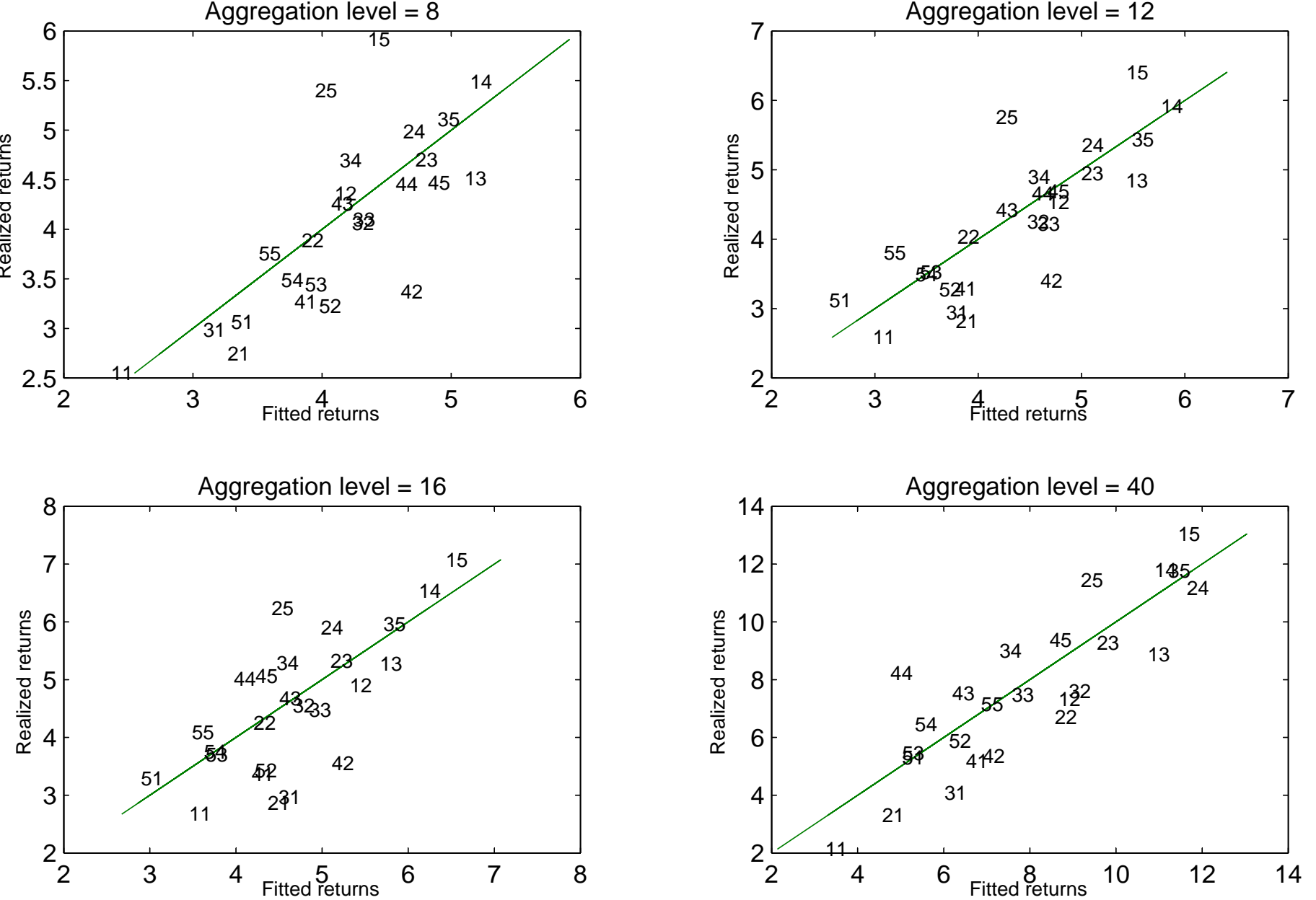
Figure 4. Realized vs. fitted returns on FF portfolios - C-CAPM
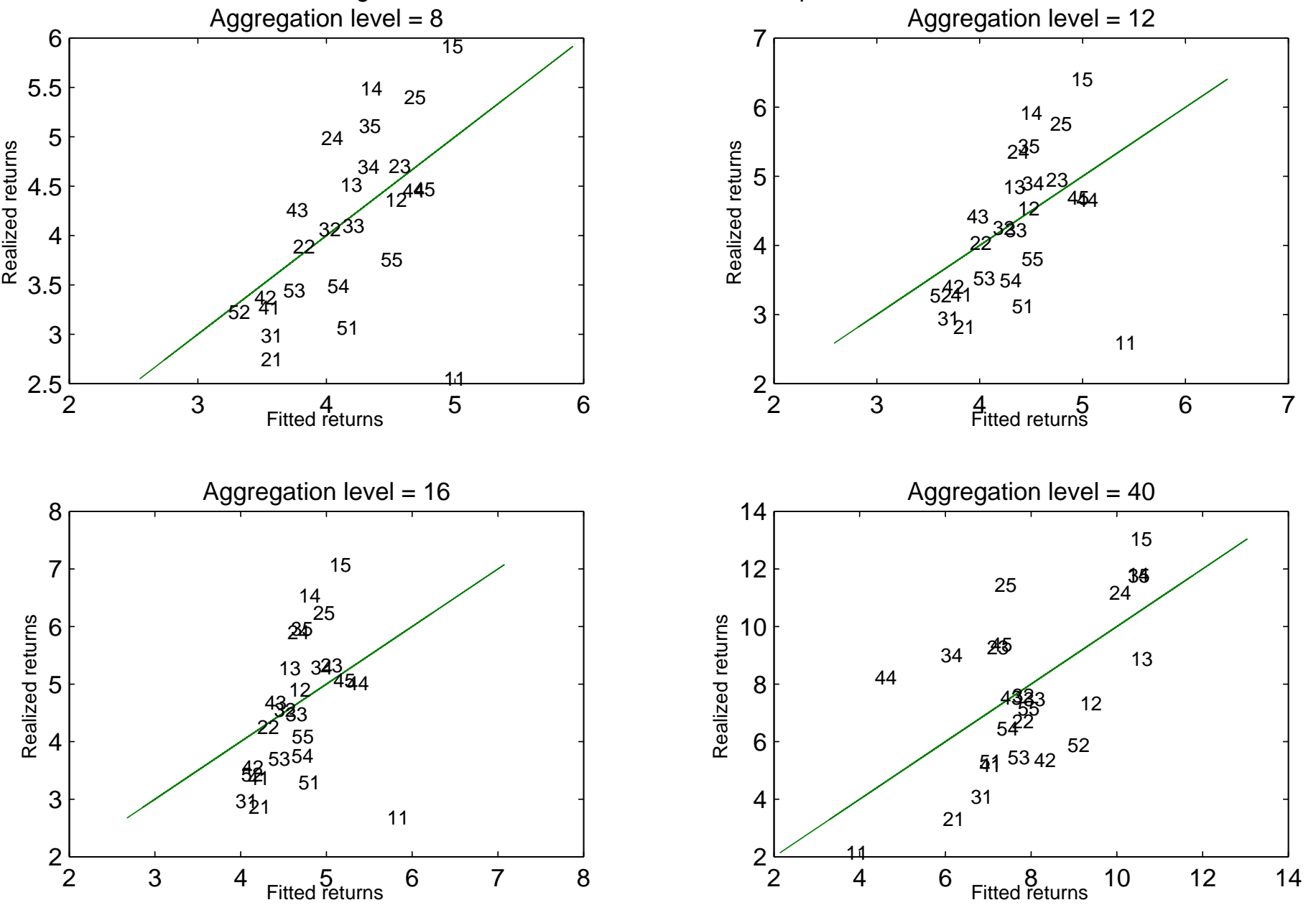
Figure 5. Realized vs. fitted returns on FF portfolios - C-CAPM scaled by pmv
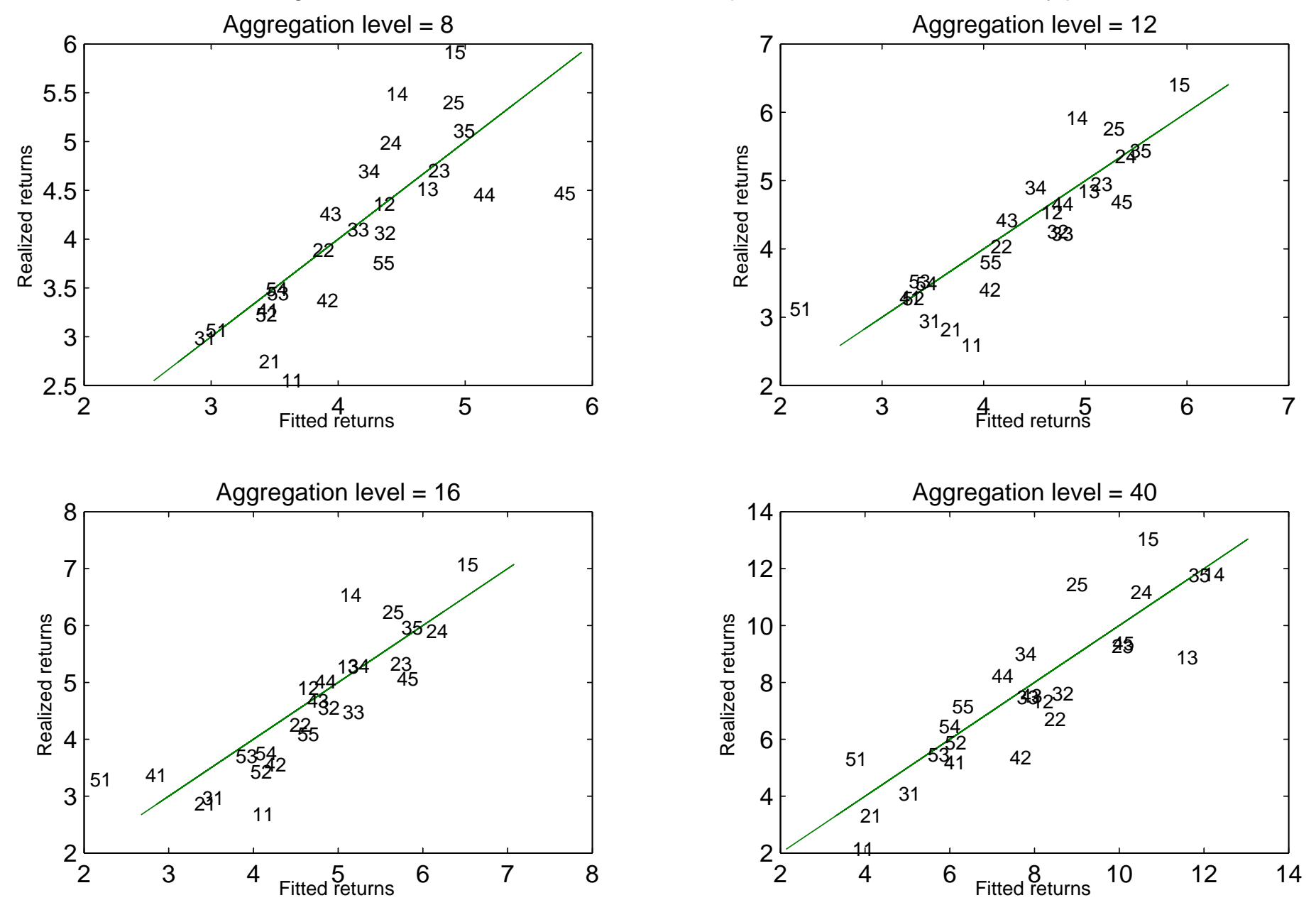
Figure 6. Betas when pmv is high - 3 years

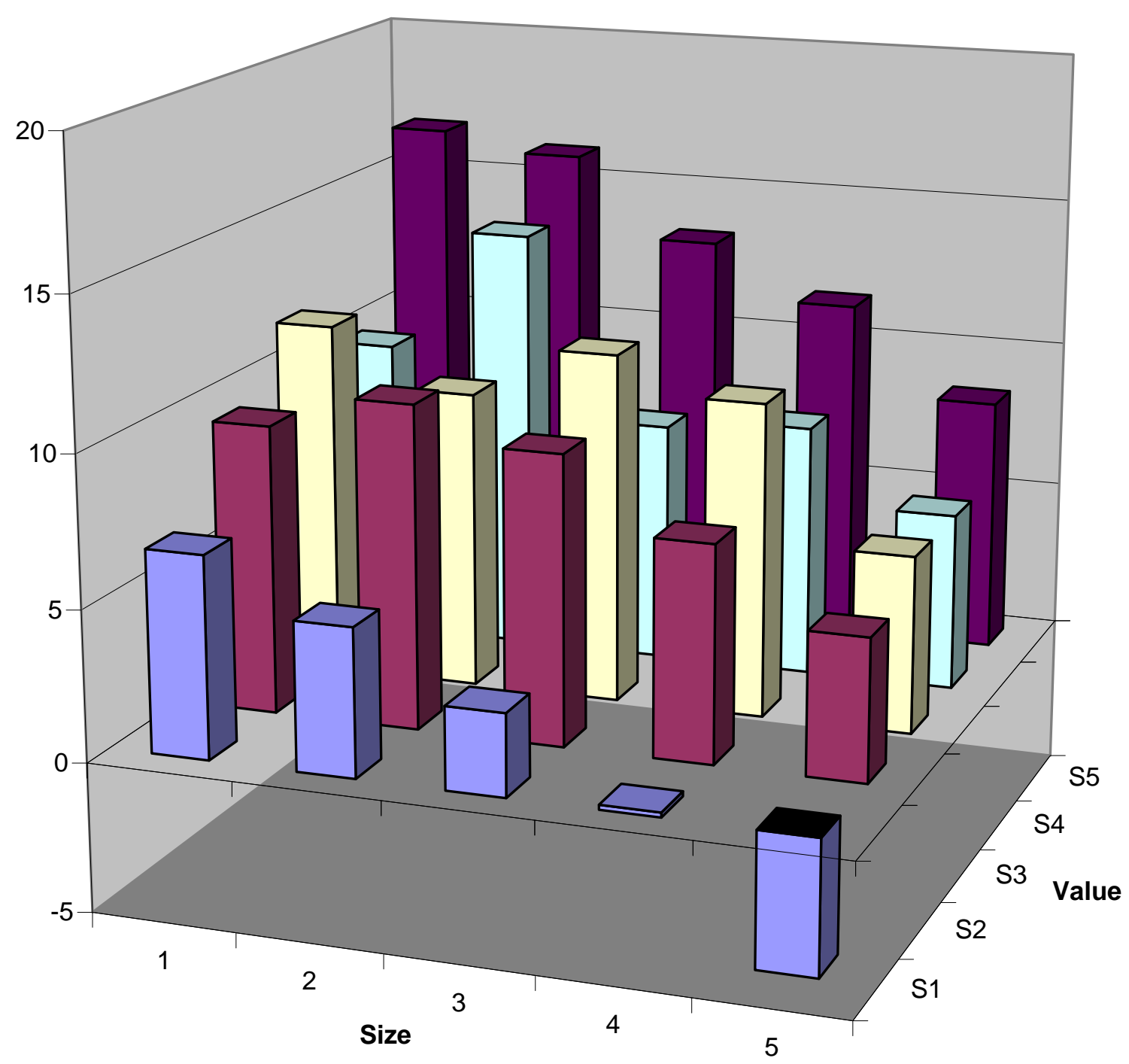


Figure 7. Betas when pmv is low - $\mathbf{3}$ years

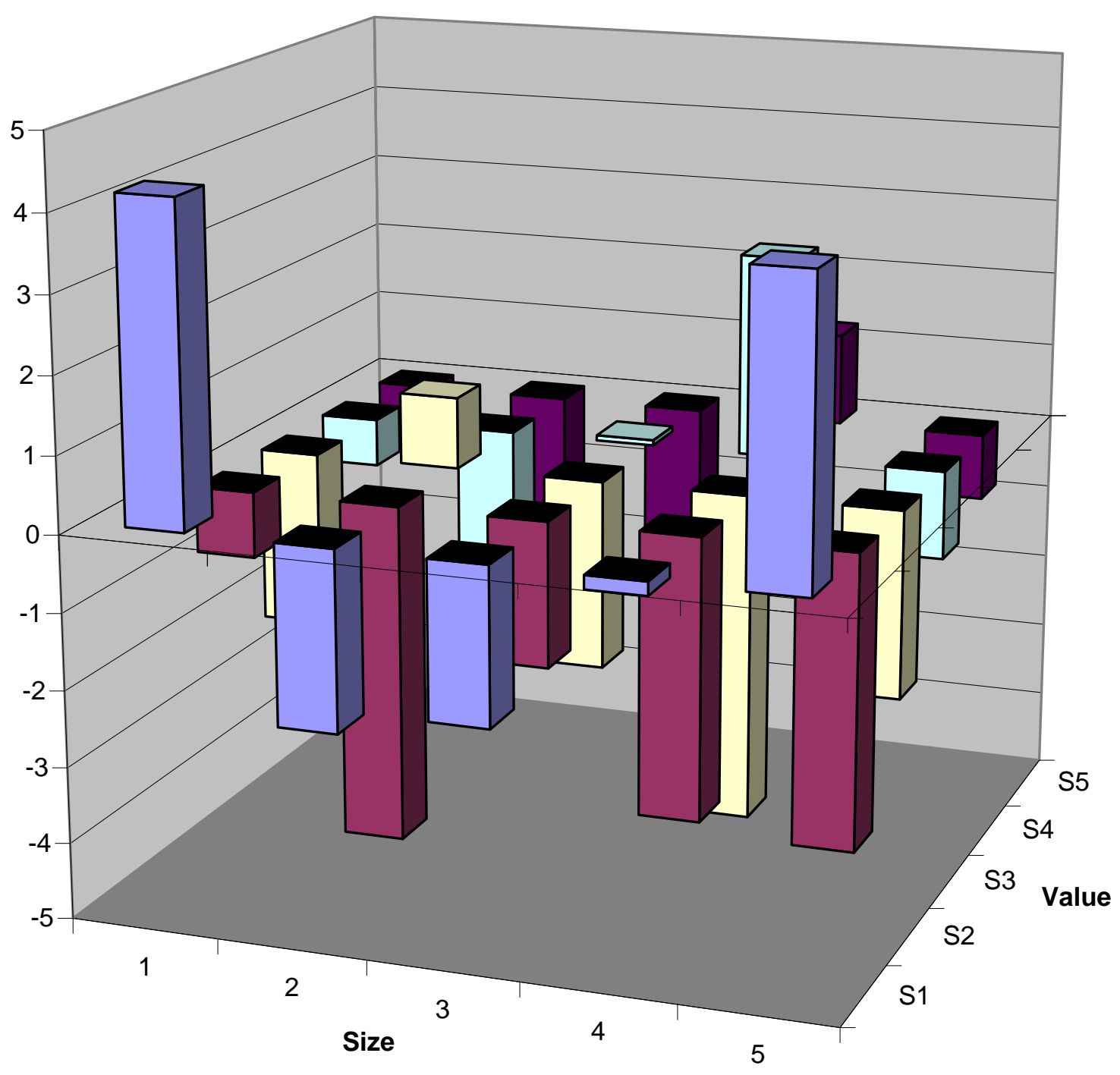

